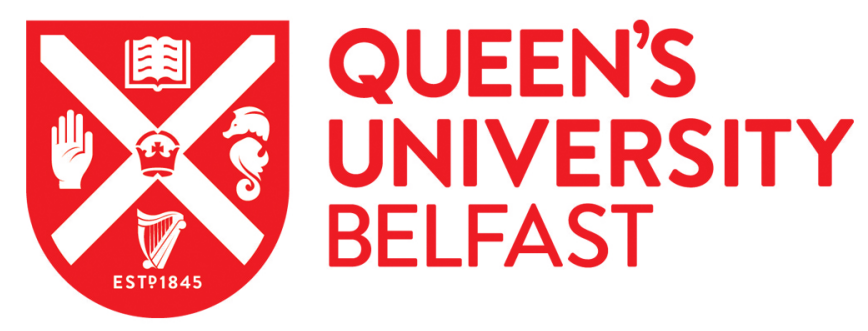

\title{
Survival for oesophageal, stomach and small intestine cancers in Europe 1999-2007: Results from EUROCARE-5
}

Anderson, L. A., Tavilla, A., Brenner, H., Luttmann, S., Navarro, C., Gavin, A. T., Holleczek, B., Johnston, B. T., Cook, M. B., Bannon, F., \& Sant, M. (2015). Survival for oesophageal, stomach and small intestine cancers in Europe 1999-2007: Results from EUROCARE-5. European Journal of Cancer, 51(15), 2144-2157. https://doi.org/10.1016/j.ejca.2015.07.026

Published in:

European Journal of Cancer

Document Version:

Peer reviewed version

Queen's University Belfast - Research Portal:

Link to publication record in Queen's University Belfast Research Portal

Publisher rights

(c) 2015 Elsevier Ltd. This manuscript version is made available under the CC-BY-NC-ND 4.0 license http://creativecommons.org/licenses/by$\mathrm{nc}-\mathrm{nd} / 4.0 /$, which permits distribution and reproduction for non-commercial purposes, provided the author and source are cited.

\section{General rights}

Copyright for the publications made accessible via the Queen's University Belfast Research Portal is retained by the author(s) and / or other copyright owners and it is a condition of accessing these publications that users recognise and abide by the legal requirements associated with these rights.

Take down policy

The Research Portal is Queen's institutional repository that provides access to Queen's research output. Every effort has been made to ensure that content in the Research Portal does not infringe any person's rights, or applicable UK laws. If you discover content in the

Research Portal that you believe breaches copyright or violates any law, please contact openaccess@qub.ac.uk. 
Survival for oesophageal, stomach and small intestine cancers: results from EUROCARE-5.

Key words: oesophageal, stomach, small intestine, survival, Europe

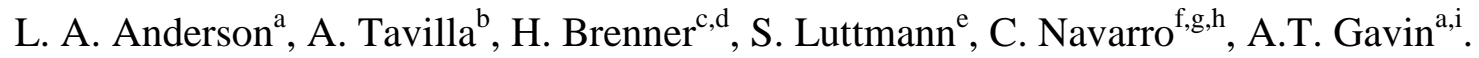
B. Holleczek ${ }^{\mathrm{j}}$, B.T. Johnston ${ }^{\mathrm{k}}$, M.B. Cook ${ }^{1}$, F. Bannon ${ }^{\mathrm{a}}$, M. Sant ${ }^{\mathrm{m}}$ and the EUROCARE-5 Working Group ${ }^{14}$.

${ }^{a}$ Centre for Public Health, School of Medicine, Dentistry and Biomedical Science, Queen's University Belfast, Northern Ireland.

${ }^{\mathrm{b}}$ National Center of Epidemiology, Italian National Institute of Health, Rome, Italy.

${ }^{\mathrm{c}}$ Division of Clinical Epidemiology and Aging Research and Division of Preventive Oncology, German Cancer Research Center (DKFZ), Heidelberg, Germany.

${ }^{\mathrm{d}}$ German Cancer Consortium (DKTK), German Cancer Research Center (DKFZ), Heidelberg, Germany.

${ }^{\mathrm{e}}$ Bremen Cancer Registry, Leibniz-Institute for Prevention Research and Epidemiology BIPS, Bremen, Germany.

${ }^{\mathrm{f}}$ Department of Epidemiology, Murcia Regional Health Council, IMIB-Arrixaca, Murcia, Spain.

${ }^{\text {g }}$ CIBER Epidemiología y Salud Pública (CIBERESP), Spain. 
${ }^{\mathrm{h}}$ Department of Health and Social Sciences, Universidad de Murcia, Murcia, Spain.

${ }^{i}$ Northern Ireland Cancer Registry, Queen's University Belfast, Northern Ireland.

${ }^{\mathrm{j} S a a r l a n d}$ Cancer Registry, Präsident Baltz Straße 5, 66119 Saarbrücken, Germany.

${ }^{\mathrm{k}}$ Belfast Health and Social Care Trust, Belfast, Northern Ireland.

${ }^{1}$ Division of Cancer Epidemiology and Genetics, National Cancer Institute, National Institutes of Health, Maryland, USA.

${ }^{\mathrm{m}}$ Analytical Epidemiology and Health Impact Unit. Department of Preventive and Predictive Medicine, Fondazione IRCCS Istituto Nazionale dei TumoriVia Venezian 1, 20133, Milan, Italy.

${ }^{14}$ EUROCARE-5 Working Group: Austria: M. Hackl, N. Zielonke (Austrian CR); W. Oberaigner (Tyrol CR); Belgium: E. Van Eycken, K. Henau (Belgian CR); Bulgaria: Z. Valerianova, N. Dimitrova (Bulgarian CR); Croatia: M. Sekerija (Croatian CR); Czech Republic: M. Zvolský, L. Dušek (Czech National CR); Denmark: H. Storm, G. Engholm (Danish Cancer Society); Estonia: M. Mägi (Estonian CR); T. Aareleid (National Institute for Health Development, Tallinn); Finland: N. Malila, K. Seppä (Finnish CR); France: M. Velten (Bas Rhin CR); X. Troussard (Basse Normandie Haematological malignancies CR); V. Bouvier, G. Launoy (Calvados Digestive Tract Registry); A. V. Guizard (Calvados, General CR); J. Faivre*, A. M. Bouvier (Côte d'Or Digestive Tract Registry, Burgundy); P. Arveux (Côte d'Or Gynaecologic CR); M. Maynadié (Côte d'Or Haematological Malignancies CR); A. S. Woronoff (Doubs CR); M. Robaszkiewicz (Finistère Digestive Tract Registry); I. Baldi (Gironde CNS CR); A. Monnereau (Gironde Haematological Malignancies CR); B. Tretarre (Hérault CR); N. Bossard* (Hospices Civils de Lyon); A. Belot (Hospices Civils de Lyon, FRANCIM); M. Colonna* (Isère CR); F. Molinié (Loire-Atlantique CR); S. Bara (Manche CR); C. Schvartz (Marne \& Ardennes, Thyroid CR); B. Lapôtre-Ledoux (Somme CR); P. Grosclaude (Tarn CR); Germany: M. Meyer (Bavaria CR); R. Stabenow (Berlin CR; Brandenburg CR; Mecklenburg-West Pomerania CR; Saxony CR; Saxony-Anhalt CR; Thüringen CR); S. Luttmann, A. Eberle (Bremen CR, Leibniz Institute for Prevention Research and Epidemiology); H. Brenner (German Cancer Research Center); A. Nennecke (Hamburg CR); J. Engel, G. Schubert-Fritschle (Munich CR); J. Kieschke (Niedersachsen CR); J. Heidrich (North Rhine-Westphalia CR); B. Holleczek (Saarland CR); A. Katalinic* (Schleswig-Holstein CR); Iceland: J. G. Jónasson, L. Tryggvadóttir (Icelandic CR); Ireland: H. Comber (National Cancer Registry Ireland); Italy: G. Mazzoleni, A. Bulatko (Alto Adige CR); C. Buzzoni (Associazione Italiana Registri Tumore); A. Giacomin (Biella CR); A. Sutera Sardo, P. Mancuso (Catanzaro CR); S. Ferretti (Ferrara CR); E. Crocetti, A. Caldarella (Firenze-Prato CR); G. Gatta*, M. Sant*, H. Amash, C. Amati, P. Baili*, F. Berrino*, S. Bonfarnuzzo, L. Botta, F. Di Salvo, R. Foschi, C. Margutti, E. Meneghini, P. Minicozzi, 
A. Trama (Fondazione IRCCS Istituto Nazionale dei Tumori, Milan); D. Serraino, L. Dal Maso (Friuli Venezia Giulia CR, CRO Aviano National Cancer Institute); R. De Angelis*, M. Caldora, R. Capocaccia*, E. Carrani, S. Francisci*, S. Mallone, D. Pierannunzio, P. Roazzi, S. Rossi, M. Santaquilani, A. Tavilla (Istituto Superiore di Sanità, Rome); F. Pannozzo, S. Busco (Latina CR); L. Bonelli, M. Vercelli (Liguria CR, IRCCS AOU SM-IST); V. Gennaro (Liguria Mesothelioma CR); P. Ricci (Mantova CR); M. Autelitano, G. Randi (Milano CR); M. Ponz De Leon (Modena colorettali $C R$ ); C. Marchesi, C. Cirilli (Modena CR); M. Fusco, M. F. Vitale (Napoli 3 South CR); M. Usala (Nuoro CR); A. Traina, R. Staiti (Palermo Breast CR); F. Vitale, B. Ravazzolo (Palermo CR); M. Michiara (Parma CR); R. Tumino (Ragusa CR); P. Giorgi Rossi, E. Di Felice (Reggio Emilia CR); F. Falcini (Romagna CR); A. Iannelli (Salerno CR); O. Sechi, R. Cesaraccio (Sassari CR); S. Piffer (Servizio Epidemiologia Clinica e Valutativa, Trento); A. Madeddu, F. Tisano (Siracusa CR); S. Maspero, A. C. Fanetti (Sondrio CR); R. Zanetti, S. Rosso (Torino CR); P. Candela, T. Scuderi (Trapani CR); F. Stracci, F. Bianconi (Umbria CR); G. Tagliabue, P. Contiero (Varese Province CR, Fondazione IRCCS Istituto Nazionale dei Tumori); A. P. Dei Tos, S. Guzzinati (Veneto CR); Latvia: S. Pildava (Latvian CR); Lithuania: G. Smailyte (Lithuanian CR); Malta: N. Calleja, D. Agius (Malta National Cancer Registry, Health Information and Research); Norway: T. B. Johannesen (Norwegian CR); Poland: J. Rachtan (Cracow CR); S. Góźdź, R. Mężyk (Kielce CR); J. Błaszczyk, M. Bębenek (Lower Silesia CR, Wroclaw); M. Bielska-Lasota* (National Institute of Public HealthNIH, Warszawa); Portugal: G. Forjaz de Lacerda (Açores CR); M. J. Bento, C. Castro (Northern Portugal CR); A. Miranda, A. Mayer-da-Silva (Southern Portugal CR); Romania: F. Nicula, D. Coza (The Oncology Institute "I. Chiricuta", Cluj-Napoca); Slovakia: C. Safaei Diba (Slovakian National $C R$ ); Slovenia: M. Primic-Zakelj* (Cancer Registry of Republic of Slovenia); Spain: E. Almar, C. Ramírez (Albacete. Castilla-La Mancha CR); M. Errezola, J. Bidaurrazaga (Basque Country CR); A. Torrella-Ramos (Castellón-Valencia CR, breast); J. M. Díaz García, R. Jimenez-Chillaron (Cuenca $C R$ ); R. Marcos-Gragera*, A. Izquierdo Font (Girona CR); M. J. Sanchez, D. Y. L. Chang (Granada CR, CIBERESP, ibs.Granada); C. Navarro, M. D. Chirlaque (Murcia CR, CIBERESP, IMIBArrixaca); C. Moreno-Iribas, E. Ardanaz (Navarra CR, CIBERESP); J. Galceran, M. Carulla (Tarragona CR); Sweden: M. Lambe* (Regionalt cancercentrum and Karolinska Institutet); S. Khan (Swedish CR); Switzerland: M. Mousavi (Basel CR); C. Bouchardy, M. Usel (Geneva CR); S. M. Ess, H. Frick (Grisons-Glarus CR); M. Lorez (NICER); S. M. Ess, C. Herrmann (St. Gallen CR); A. Bordoni, A. Spitale (Ticino $C R$ ); I. Konzelmann (Valais $C R$ ); The Netherlands: O. Visser, R. Verhoeven (The Netherlands CR); UK-England: M. Coleman*, C. Allemani, B. Rachet (London School of Hygiene and Tropical Medicine); J. Verne*, N. Easey, G. Lawrence, T. Moran, J. Rashbass, M. Roche, J. Wilkinson (Public Health England); UK-Northern Ireland: A. Gavin, C. Donnelly (Northern Ireland CR); UK-Scotland: D. H. Brewster (Scottish CR); UK-Wales: D. W. Huws, C. White (Welsh Cancer Intelligence and Surveillance Unit); R. Otter*.

*EUROCARE Steering Committee

\section{Corresponding author details:}

Dr Lesley Anderson

Centre for Public Health

Queen's University Belfast 
Institute for Clinical Sciences Block B

Grosvenor Road

Belfast

BT12 6BJ

Tel: ++44 (0)2890632315

Fax: ++44 (0)28 90235900

E-mail: 1.anderson@qub.ac.uk

Acknowledgements: We thank Chiara Margutti, Simone Bonfarnuzzo and Camilla Amati for secretarial assistance.

\section{Role of funding source}

The study was funded by the Compagnia di San Paolo, the Fondazione Cariplo Italy, the Italian Ministry of Health (Ricerca Finalizzata 2009, RF-2009-1529710) and the European Commission (European Action Against Cancer, EPAAC, Joint Action No20102202). The Northern Ireland Cancer Registry is supported by the Public Health Agency for N. Ireland. Dr Michael Cook is funded by US Federal Funds. The Compagnia di San Paolo, the Fondazione Cariplo Italy, the Italian Ministry of Health (Ricerca Finalizzata 2009, RF-2009-1529710) and the European Commission (European Action Against Cancer, EPAAC, Joint Action No20102202). The funding sources had no role in study design, the collection, analysis or interpretation of data, the writing of the report, or the decision to submit the article for publication. 


\begin{abstract}
Background

European regional variation in cancer survival was reported in the EUROCARE-4 study for patients diagnosed in 1995-1999. Relative survival (RS) estimates are here updated for patients diagnosed with cancer of the oesophagus, stomach, and small intestine from 2000 to 2007 . Trends in RS from 1999-2001 to 2005-2007 are presented to monitor and discuss improvements in patient survival in Europe.
\end{abstract}

\title{
Materials and Methods
}

EUROCARE-5 data from 29 countries (87 cancer registries) were used to investigate 1and 5-year RS. Using registry-specific life-tables stratified by age, gender, and calendar year, age-standardised 'complete analysis' RS estimates by country and region were calculated for Northern, Southern, Eastern and Central Europe, and for Ireland and United Kingdom (UK). Survival trends of patients in periods 1999-2001, 2002-2004, and 20052007 were investigated using the 'period' RS approach. We computed the 5-year RS conditional on surviving the first year (5-year conditional survival), as the ratio of agestandardised 5-year RS to 1-year RS.

\section{Results}

Oesophageal cancer 1- and 5-year RS (40\% and 12\%, respectively) remained poor in Europe. Patient survival was worst in Eastern (8\%), Northern (11\%), and Southern Europe (10\%). Europe-wide, there was a 3\% improvement in oesophageal cancer 5-year survival by 2005-2007, with Ireland and the UK (3\%), and Central Europe (4\%) showing large improvements. 
Europe-wide, stomach cancer 5-year RS was 25\%. Ireland and UK (17\%) and Eastern Europe (19\%) had the poorest 5-year patient survival. Southern Europe had the best 5year survival (30\%), though only showing an improvement of $2 \%$ by $2005-2007$.

Small intestine cancer 5-year RS for Europe was 48\%, with Central Europe having the best (54\%), and Ireland and UK the poorest (37\%). Five-year patient survival improvement for Europe was $8 \%$ by $2005-2007$, with Central, Southern, and Eastern Europe showing the greatest increases $(\geq 9 \%)$.

\section{Conclusions}

Survival for these cancer sites, particularly oesophageal cancer, remains poor in Europe with wide variation. Further investigation into the wide variation, including analysis by histology and anatomical sub-site, will yield insight to better monitor and explain the improvements in survival observed over time. 


\section{Introduction}

This article focuses on European relative survival (RS) estimates and trends for oesophageal, stomach and small intestine cancer patients, diagnosed up to 2007, with follow-up to December $31^{\text {st }} 2008$, as part of EUROCARE-5. Regional variation in RS estimates throughout Europe has been consistently reported for cancer patients, including upper gastrointestinal tract cancers, diagnosed in 1990-1994 [1], 1995-1999 [2] and 1999$2007[3]$.

Oesophageal cancer ranks as the eighth most common cancer worldwide with approximately 5 cases per 100,000 diagnosed in Europe annually [4]. Two main histological subtypes, adenocarcinoma (OAC) and squamous cell carcinoma (OSCC), display regional variation in incidence across Europe [5]. Stomach cancer is the third most common cause of cancer death globally [6]. Wide variation in stomach cancer incidence across Europe has been reported with recent declines in most European countries as a result of lifestyle changes, Helicobacter pylori detection and cancer treatment. Incidence of non-cardia tumors is high in Southern Europe [7] which, correspondingly, has the best 5-year patient survival [3]. While the small intestine comprises $90 \%$ of the length of the bowel, small intestine cancers are rare with an agestandardised incidence rate of 2 per 100,000 person-years in the USA [8] with lower incidence rates reported within Europe [9]. Small intestine cancers exhibit a diverse histology with adenocarcinomas, carcinoid (now classified as neuroendocrine), lymphomas and sarcomas most common [10]. Incidence of small intestine cancers, particularly neuroendocrine malignancies, have increased in the USA [11,12] and Sweden [13], likely as a result of improved detection and classification. Neuroendocrine small intestine cancers are the most common histological subtype and confer superior prognosis 
compared to other small intestine entities [12]. Incidence of epithelial small intestine cancers is reportedly highest in Northern and lowest in Eastern Europe [14]; possibly due to geographic differences in diagnostic testing and variable capture by cancer registries.

\section{Methods}

Methods used for the analysis of EUROCARE-5 data are described in a dedicated paper in this EJC issue [15]. Briefly, survival data were obtained from 29 countries, 21 with $100 \%$ national coverage, from 87 cancer registries. Countries were grouped into Northern, Central, Southern and Eastern Europe and Ireland and UK.

All patients diagnosed with a primary and malignant oesophageal, stomach or small intestine cancer, as identified by topography codes C15, C16 (cardia C16.0 and noncardia C16.1-C16.6) and C17, respectively, of the International Classification of Diseases for Oncology, $3^{\text {rd }}$ edition (ICD-O-3), diagnosed from 2000-2007 were included. Patients with morphology codes 9590-9989 (ICD-O-3), or who were diagnosed by death certificate only (DCO), autopsy only, or censored with null survival time, were excluded. Patients were not excluded if they had a previous primary tumour. All the registries with less than $13 \%$ of DCO (for all cancers combined) were included in the analysis.

One-year RS, 5-year RS and 5-year RS conditional on surviving the first year after diagnosis (5-year conditional) were estimated using the 'complete' cohort approach for patients diagnosed 2000-2007 (with follow-up to 2008) stratified by gender and agegroup (i.e. 15-44, 45-54, 55-64, 65-74, 75 years or older) as previously described [15]. Age standardised survival [16] and European average estimates [15] are also provided. Survival trends were estimated for countries with cases diagnosed between 1999 and 
2007 ( $n=24$ countries) with follow-up to 2008, using the 'period' approach [17] to reliably predict 5-year survival in the years, 1999-2001, 2002-2004, and 2005-2007.

\section{Results}

Oesophageal, stomach and small intestine cancers were more common in men than women, Table 1. Some countries in Eastern Europe had a high percentage of DCO cases. Elsewhere in Europe the highest DCO rates were reported in Germany. Mean age at diagnosis for oesophageal, stomach and small intestine cancers ranged from 60.7-71.6, 66.8-73.1 and 60.5-68.9 years, respectively, Table 1.

\section{Oesophageal cancer}

European average 1-year age-standardised RS was $39.9 \%$, with $12.4 \%$ of patients surviving 5-years, Figure 1. Patients in the Central Europe region, particularly Belgium, had the best survival in Europe while survival was poorest in Eastern Europe. Lithuania and Bulgaria had the lowest 5-year RS estimates. Conditional 5-year survival displayed less heterogeneity across Europe, Figure 1.

Survival, at all follow-up time points investigated, decreased with increasing age, Figure

1. One-, 3- and 5-year age-standardised RS was higher in women than men across all follow-up time points, Figure 1.

Overall oesophageal cancer 5-year age-standardised patient survival improved from $9.9 \%$ to $12.6 \%$ between $1999-2001$ and 2005-2007. Graphs of 5-year RS by region and Europe 
overall are presented in Supplement 1. The largest regional improvements in 5-year RS were observed in Ireland and UK and Central Europe with limited improvements observed in Eastern or Southern Europe, (Table 2 and Supplement 1). Similar improvements in patient survival were noted between 1999-2001 and 2002-2004, and between 2002-2004 and 2005-2007 for most regions.

\section{Stomach Cancer}

One-year age-standardised RS for stomach cancer patients reached almost 50\% with substantial regional variation, see Figure 2. While the Eastern Europe region had the poorest 1-year RS (38.4\%), the 5-year RS was lowest in Ireland and UK (17.2\%) region, with similar survival across all UK countries. Southern Europe had the best 5-year patient survival (29.6\%) in Europe. While Eastern Europe had low 1- and 5-year RS, 5-year conditional survival was better than in Northern Europe, and Ireland and UK. Wide variation among countries was identified in 5-year RS estimates from $11.9 \%$ in Bulgaria to $34.5 \%$ in Iceland. Survival, at all follow-up time points investigated, decreased with increasing age, and women appeared to fare better than men.

Overall 5-year patient survival increased absolutely by less than $2 \%$ points across Europe between 1999-2001 and 2005-2007 (Table 3 and Supplement 2). The most marked improvement in patient survival was in Slovenia from 1999-2001 (RS 20.8\%) to 20022004 (RS 27.1\%), Table 3. Although no change was observed in 5-year RS in Northern Europe, improved patient survival was evident in Denmark and Sweden with a decrease 
in 5-year RS observed in Finland. The Netherlands had low RS compared to the rest of Central Europe across all periods.

Southern and Central Europe had better patient survival for cardia and non-cardia cancers than other regions, Table 4. Survival for non-cardia cancer patients was significantly higher than for cardia cancer patients, Table 4. In Eastern Europe, as in Southern and Central Europe, patients with non-cardia cancer predominated, Table 4.

\section{Small Intestine Cancer}

Small intestine cancer 1- and 5-year RS was $67.9 \%$ and $47.9 \%$, respectively, see Figure 3. Ireland and UK was the region with the worst 1-year patient survival at 58.8\%. Croatia was the country with the poorest 1-year RS (53.3\%). The Central Europe region had the best 5-year RS for small intestine cancer (53.9\%) with the poorest in the Ireland and UK region $(36.9 \%)$. Wide country variation was identified in 5-year RS from $23.5 \%$ in Malta to $58.6 \%$ in Switzerland. Five-year conditional survival in patients in Ireland and UK remained significantly below the European average, Figure 3.

European patient survival declined with increasing age. Overall 1-, 3- and 5-year agestandardised RS were slightly higher in women compared to men; particularly evident in younger patients, Figure 3.

Overall 5-year RS increased from $40.5 \%$ to $48.7 \%$ from 1999-2001 until 2005-2007

(Table 5 and supplement 3 ). The largest improvements (>10\% points) in patient survival 
were observed in Italy, Austria, Czech Republic and Finland. All regions, except Ireland and UK, showed a significant increase in survival from 1999-2001 to 2005-2007.

\section{Discussion}

European wide variation in patient survival was observed for all three cancer sites investigated between regions. Country-specific patient survival also displayed wide variation with several countries showing inconsistent estimates to their region, including Denmark, the Netherlands, Bulgaria and Croatia. Survival of patients improved modestly from 1999-2001 until 2005-2007 for all cancer sites. Oesophageal and stomach cancer 5year RS for Europe remained very poor. Small intestine cancer had the best overall 5-year RS in Europe and displayed the largest improvement in patient survival.

\section{Oesophageal cancer}

European 1- and 5-year RS for oesophageal cancer patients remained poor (35.8\% and $10.6 \%$, respectively). With the exception of Central Europe, which maintained the highest patient survival compared with other European regions as reported in EUROCARE-4 [18], RS in other European regions remained below that reported in the USA [19]. Eastern Europe, where OSCC predominates, continued to have the worst RS. Geographical differences in the proportion of oesophageal cancer patients with histology 'not otherwise specified' between regions may account for some of these disparities (data not shown). Additionally, differences in diagnostic accuracy may also account for regional variation with potential misclassification of gastro-oesophageal tumours [20,21]. Cancer stage is a major predictor of cancer patient survival and differences in stage distribution between countries and regions, as a result of early detection and/or diagnostic 
practices, could also account for some of the observed disparity seen in Eastern Europe $[22,23]$.

Five-year RS for oesophageal cancer patients, for Europe as a whole, increased marginally from $9.8 \%$ in $1999-2001$ to $12.6 \%$ in $2005-2007$. Central Europe and Ireland and UK demonstrated the most marked improvement. This may be explained by improvements in surgical techniques, adjuvant therapy, earlier diagnosis and/or centralisation of treatment. The trends in Europe in mortality [24] and incidence [25] in oesophageal cancer vary markedly across the countries in the study, but generally there is tight correlation between them, suggesting that improvements in survival are not due to over-diagnosis arising from increased surveillance. Variation in incidence trends may be caused by regional changes in the risk-factor prevalence [26]. Obesity may be increasing the incidence of OAC particularly in northern and western Europe, while reduction in tobacco and alcohol consumption is reducing the incidence of OSCC [26]. The generally better prognosis of patients diagnosed with EAC is not consistent across Europe [18].

Centralisation of treatment has produced a marked improvement in oesophageal cancer patient survival with many European countries introducing such strategies in recent years. Ireland and UK demonstrated comparatively better patient survival improvements for oesophageal cancer than most Northern European countries in both time frames investigated and in line with the centralisation of cancer services for oesophagogastric cancer surgery implemented in the UK in 2001. While hospitals performing more than 40 oesophagectomies annually had lower 30-day postoperative mortality, this may not fully explain regional differences in oesophageal or gastric cancer patient survival [27]. Other factors, as highlighted by the International Benchmarking Partnership, may be important such as late diagnosis, differences in public awareness of cancer symptoms, cancer stage, 
morphology and topography, presence of co-morbidities, lifestyle factors such as cigarette smoking, and access to optimum care [28]. Body mass index has also been shown to be a prognostic marker for OSCC [29]. The fact that 5-year conditional patient survival is rather similar across Europe indicates relevant differences in short term mortality and points towards early diagnosis and access to care as important areas to consider with regards to improvement of oesophageal cancer patient treatment and standardisation of care.

\section{Stomach cancer}

One- and 5-year RS for stomach cancer patients remained low particularly in comparison to 5-year survival of around 69\% achieved in Asia [30]. Compared to Europe, stomach cancer incidence in Asia is high, with a predominance of non-cardia tumours which have better patient survival [31]. Screening programs and more aggressive treatment undoubtedly contribute to the superior survival of patients seen in Asia but similar strategies are unlikely to be cost-effective in comparatively low incidence countries within Europe. Histological and staging variability across Europe may account for some of the differences in stomach cancer patient survival observed between countries. Patient survival improved overall in Europe from 1999-2001 to 2005-2007 particularly in Denmark and the Czech Republic. Both mortality [20] and incidence [32] rates for stomach cancer continue to fall for most countries during the period of this study, suggesting no appreciable surveillance-driven over-diagnosis that could compromise estimated survival improvement. A recent report using data from the World Health Organisation reported lower stomach cancer mortality from 2000 onwards in the UK, the USA, Japan and several European countries [33]. Centralisation of treatment for gastric cancer was implemented in several European countries, including the UK, Denmark and 
the Netherlands, in recent years despite reports of no survival benefit $[27,34]$ for patients. While 5-year RS was worst in Ireland and UK, improvements in the most recent time period were observed particularly in Wales and England. While delayed diagnosis, first line treatment, or post-operative mortality could explain the patient survival disadvantage in Ireland and UK, other factors appear to be important given the poor 5-year conditional patient survival. Lifestyle differences such as smoking behaviour, co-morbidities, cancer stage and/or subtype could explain the variability observed across countries.

The decreasing 5-year RS in Finland and Norway could be related to the marked decrease in incidence, mainly affecting distal stomach cancer [35], in these countries. Patients with distal stomach cancer have better prognosis, as presented in this report, and this cancer is more responsive to preventative measures than cancers arising in the cardia or proximal stomach. As an effect of this selective incidence decrease, patient with proximal cancers, who carry a worse prognosis, may have become relatively more frequent over time.

\section{Small intestine cancer}

European 1- and 5-year RS for patients with epithelial small bowel carcinomas diagnosed from 1978-2002 were comparatively lower than those reported here for all small intestine cancers, excluding lymphomas [14]. Incidence of epithelial small intestine cancers are similar in Ireland and UK and Northern and Southern Europe [14] despite variation in RS. Differences in cancer stage at diagnosis and subtype throughout Europe could explain the reported variations in patient survival. The EUROCARE-5 data encompasses all small intestine cancer histologies with the exception of lymphomas. Small intestine sarcomas reportedly have worse prognosis than neuroendocrine cancers which have a more favourable outcome $[8,36]$. Small intestine cancers are notoriously difficult to diagnose 
due to their vague symptoms. Delays in diagnosis and treatment of small intestine cancer patients are associated with poorer prognosis [37]. One-year RS was lower in Ireland and UK as previously reported [14], and also in Denmark and several Eastern European countries, suggesting that delayed diagnosis, at patient, primary care or referral stages, might be an important factor. This would not however explain the poorer 5-year conditional survival estimates in Ireland and UK, Denmark and Malta for those patients who survived the first year post diagnosis.

Improved survival is reported across all European regions particularly in Northern, Central and Eastern Europe for small intestine cancer patients. Increasing trends in small intestine cancer incidence has been reported [11,12,13,38,39] but mortality rates have remained stable or slightly increasing [38,39]. Given the low incidence and mortality rates, and the heterogeneity of tumour types, it is difficult to say whether effective therapy has increased patient survival [40]. Recent improvements in treatment of small intestine sarcomas, with the use of tyrosine kinase inhibitors since 2001 [41] may have influenced patient survival. Due to the low incidence of gastrointestinal stromal tumours [42], a rare sarcoma sub-type, the effect on patient survival in large datasets like EUROCARE is difficult to measure without ad hoc analyses.

Detailed discussion of the strengths and limitations of the EUROCARE-5 data are available in the article by Rossi et al. in this issue [15]. Increasing survival trends after 5 years of follow-up were found in patients with poor prognosis cancer and aged 75 year and older for Austria, Croatia, Germany, Poland and Slovakia, and may be related to difficulties in the ascertainment of life status [43] or to DCO proportions [15]. Survival estimates from these countries should be interpreted with caution. However, comparing 
individual countries may provide more meaningful assessment of reasons for disparities in patient survival; this is limited, however, for cancers with low incidence estimates such as small intestine and oesophageal cancer as the standard errors become large. In addition, the \% DCO statistic for each country and cancer are available in Table 1, and should inform comparisons being made between individual countries' patient survival estimates [44].

\section{Conclusions}

This article presents overall patient survival for three anatomical sub-sites: oesophagus, stomach and small intestine. They provide some indication of areas that need further investigation to determine the drivers of the variation in survival of cancer patients across Europe. More in-depth investigation by anatomic sub-site and histology could explain the variability observed and are planned using additional data from EUROCARE-5. The historic nature of these large collaborative studies means that recent developments in early detection, routes to treatment, changes to service provision and new treatment modalities for patients will have had insufficient time to have a visible effect. Continued monitoring of cancer survival across Europe will allow further evaluation of survival differences to further promote the widespread application of effective diagnosis and treatment modalities [45]. In summary, although improvements in survival have been reported for cancers of the oesophagus, stomach and small intestine, survival remains poor with wide variation across Europe. 


\section{References}

[1] Sant M, Aareleid T, Berrino F, Bielska Lasota M, Carli PM, Faivre J, et al. EUROCARE-3: survival of cancer patients diagnosed 1990-94--results and commentary. Ann Oncol 2003;14 Suppl 5:v61-118.

[2] Berrino F, De Angelis R, Sant M, Rosso S, Bielska-Lasota M, Lasota MB, et al. Survival for eight major cancers and all cancers combined for European adults diagnosed in 1995-99: results of the EUROCARE-4 study. Lancet Oncol 2007;8:77383. doi:10.1016/S1470-2045(07)70245-0.

[3] De Angelis R, Sant M, Coleman MP, Francisci S, Baili P, Pierannunzio D, et al. Cancer survival in Europe 1999-2007 by country and age: results of EUROCARE--5-a population-based study. Lancet Oncol 2014;15:23-34. doi:10.1016/S14702045(13)70546-1.

[4] Bosetti C, Levi F, Ferlay J, Garavello W, Lucchini F, Bertuccio P, et al. Trends in oesophageal cancer incidence and mortality in Europe. Int J Cancer 2008;122:111829. doi:10.1002/ijc.23232.

[5] Arnold M, Soerjomataram I, Ferlay J, Forman D. Global incidence of oesophageal cancer by histological subtype in 2012. Gut 2015;64:381-7. doi:10.1136/gutjnl-2014308124.

[6] Ferlay J, Soerjomataram I I, Dikshit R, Eser S, Mathers C, Rebelo M, et al. Cancer incidence and mortality worldwide: sources, methods and major patterns in GLOBOCAN 2012. Int J Cancer 2014;136:E359-86. doi:10.1002/ijc.29210. 
[7] Verdecchia A, Corazziari I, Gatta G, Lisi D, Faivre J, Forman D. Explaining gastric cancer survival differences among European countries. Int J Cancer 2004;109:737-41. doi:10.1002/ijc.20047.

[8] Qubaiah O, Devesa SS, Platz CE, Huycke MM, Dores GM. Small intestinal cancer: a population-based study of incidence and survival patterns in the United States, 1992 to 2006. Cancer Epidemiol Biomarkers Prev 2010;19:1908-18. doi:10.1158/10559965.EPI-10-0328.

[9] Haselkorn T, Whittemore AS, Lilienfeld DE. Incidence of small bowel cancer in the United States and worldwide: geographic, temporal, and racial differences. Cancer Causes Control 2005;16:781-7. doi:10.1007/s10552-005-3635-6.

[10] Schottenfeld D, Beebe-Dimmer JL, Vigneau FD. The epidemiology and pathogenesis of neoplasia in the small intestine. Ann Epidemiol 2009;19:58-69. doi:10.1016/j.annepidem.2008.10.004.

[11] Tsikitis VL, Wertheim BC, Guerrero MA. Trends of incidence and survival of gastrointestinal neuroendocrine tumors in the United States: a seer analysis. J Cancer 2012;3:292-302. doi:10.7150/jca.4502.

[12] Bilimoria KY, Bentrem DJ, Wayne JD, Ko CY, Bennett CL, Talamonti MS. Small bowel cancer in the United States: changes in epidemiology, treatment, and survival over the last 20 years. Ann Surg 2009;249:63-71.

doi:10.1097/SLA.0b013e31818e4641. 
[13] Lu Y, Fröbom R, Lagergren J. Incidence patterns of small bowel cancer in a population-based study in Sweden: increase in duodenal adenocarcinoma. Cancer Epidemiol 2012;36:e158-63. doi:10.1016/j.canep.2012.01.008.

[14] Faivre J, Trama A, De Angelis R, Elferink M, Siesling S, Audisio R, et al. Incidence, prevalence and survival of patients with rare epithelial digestive cancers diagnosed in Europe in 1995-2002. Eur J Cancer 2012;48:1417-24. doi:10.1016/j.ejca.2011.10.038.

[15] Rossi S, Baili P. Caldora M, Carrani E, Minicozzi P, Pierannunzio D et al. The EUROCARE-5 database, qality checks and methods of statistical analysis. Eur J Cancer 2015.

[16] Corazziari I, Quinn M, Capocaccia R. Standard cancer patient population for age standardising survival ratios. Eur J Cancer 2004;40:2307-16. doi:10.1016/j.ejca.2004.07.002.

[17] Brenner H, Gefeller O. An alternative approach to monitoring cancer patient survival. Cancer 1996;78:2004-10.

[18] Gavin AT, Francisci S, Foschi R, Donnelly DW, Lemmens V, Brenner H, et al. Oesophageal cancer survival in Europe: a EUROCARE-4 study. Cancer Epidemiol 2012;36:505-12. doi:10.1016/j.canep.2012.07.009.

[19] Ries LAG, Young JL, Keel GE, Eisner MP, Lin YD HM-J, editor. SEER Survival Monograph: Cancer Survival Among Adults: U.S. SEER Program, 1988-2001, Patient and Tumor Characteristics. NIH Pub. N. National Cancer Institute, SEER Program; 2007. 
[20] Buas MF, Vaughan TL. Epidemiology and risk factors for gastroesophageal junction tumors: understanding the rising incidence of this disease. Semin Radiat Oncol 2013;23:3-9. doi:10.1016/j.semradonc.2012.09.008.

[21] Marsman WA, Tytgat GNJ, ten Kate FJW, van Lanschot JJB. Differences and similarities of adenocarcinomas of the esophagus and esophagogastric junction. J Surg Oncol 2005;92:160-8. doi:10.1002/jso.20358.

[22] Walters S, Maringe C, Butler J, Brierley JD, Rachet B, Coleman MP. Comparability of stage data in cancer registries in six countries: lessons from the International Cancer Benchmarking Partnership. Int J Cancer 2013;132:676-85. doi:10.1002/ijc.27651.

[23] Maringe C, Walters S, Butler J, Coleman MP, Hacker N, Hanna L, et al. Stage at diagnosis and ovarian cancer survival: evidence from the International Cancer Benchmarking Partnership. Gynecol Oncol 2012;127:75-82. doi:10.1016/j.ygyno.2012.06.033.

[24] Bosetti C, Bertuccio P, Malvezzi M, Levi F, Chatenoud L, Negri E, et al. Cancer mortality in Europe, 2005-2009, and an overview of trends since 1980. Ann Oncol. 2013 Oct;24(10):2657-71.

[25] Lortet-Tieulent J, Renteria E, Sharp L, Weiderpass E, Comber H, Baas P, et al. Convergence of decreasing male and increasing female incidence rates in major tobacco-related cancers in Europe in 1988-2010. Eur J Cancer. 2015 Jun;51(9):114463. 
[26] Castro C, Bosetti C, Malvezzi M, Bertuccio P, Levi F, Negri E, et al. Patterns and trends in esophageal cancer mortality and incidence in Europe (1980-2011) and predictions to 2015. Ann Oncol. 2014 Jan;25(1):283-90.

[27] Dikken JL, van Sandick JW, Allum WH, Johansson J, Jensen LS, Putter H, et al. Differences in outcomes of oesophageal and gastric cancer surgery across Europe. Br J Surg 2013;100:83-94. doi:10.1002/bjs.8966.

[28] Forbes LJL, Simon AE, Warburton F, Boniface D, Brain KE, Dessaix A, et al. Differences in cancer awareness and beliefs between Australia, Canada, Denmark, Norway, Sweden and the UK (the International Cancer Benchmarking Partnership): do they contribute to differences in cancer survival? Br J Cancer 2013;108:292-300. doi:10.1038/bjc.2012.542.

[29] Watanabe M, Ishimoto T, Baba Y, Nagai Y, Yoshida N, Yamanaka T, et al. Prognostic impact of body mass index in patients with squamous cell carcinoma of the esophagus. Ann Surg Oncol 2013;20:3984-91. doi:10.1245/s10434-013-3073-8.

[30] Nashimoto A, Akazawa K, Isobe Y, Miyashiro I, Katai H, Kodera Y, et al. Gastric cancer treated in 2002 in Japan: 2009 annual report of the JGCA nationwide registry. Gastric Cancer 2013;16:1-27. doi:10.1007/s10120-012-0163-4.

[31] Yako-Suketomo H, Katanoda K. Comparison of time trends in stomach cancer mortality (1990-2006) in the world, from the WHO mortality database. Jpn J Clin Oncol 2009;39:622-3. doi:10.1093/jjco/hyp107. 
[32] Arnold M, Karim-Kos HE, Coebergh JW, Byrnes G, Antilla A, Ferlay J, et al. Recent trends in incidence of five common cancers in 26 european countries since 1988: Analysis of the european cancer observatory. Eur J Cancer. 2015 Jun;51(9):1164-87.

[33] Matsuda A, Matsuda T. Time trends in stomach cancer mortality (1950-2008) in Japan, the USA and Europe based on the WHO mortality database. Jpn J Clin Oncol 2011;41:932-3. doi:10.1093/jjco/hyr093.

[34] Van de Poll-Franse L V, Lemmens VEPP, Roukema JA, Coebergh JWW, Nieuwenhuijzen GAP. Impact of concentration of oesophageal and gastric cardia cancer surgery on long-term population-based survival. Br J Surg 2011;98:956-63. doi:10.1002/bjs.7493.

[35] Schmassmann A, Oldendorf M-G, Gebbers J-O. Changing incidence of gastric and oesophageal cancer subtypes in central Switzerland between 1982 and 2007. Eur J Epidemiol 2009;24:603-9. doi:10.1007/s10654-009-9379-y.

[36] Zeeneldin AA, Saber MM, Seif El-Din IA, Frag SA. Small intestinal cancers among adults in an Egyptian district: a clinicopathological study using a population-based cancer registry. J Egypt Natl Canc Inst 2013;25:107-14. doi:10.1016/j.jnci.2013.01.004.

[37] Bauer RL, Palmer ML, Bauer AM, Nava HR, Douglass HO. Adenocarcinoma of the small intestine: 21-year review of diagnosis, treatment, and prognosis. Ann Surg Oncol 1994;1:183-8. 1. 
[38]. Shack LG, Wood HE, Kang JY, Brewster DH, Quinn MJ, Maxwell JD, et al. Small intestinal cancer in England \& Wales and Scotland: Time trends in incidence, mortality and survival. Aliment Pharmacol Ther. 2006 May 1;23(9):1297-306.

[39]. Klint A, Engholm G, Storm HH, Tryggvadottir L, Gislum M, Hakulinen T, et al. Trends in survival of patients diagnosed with cancer of the digestive organs in the nordic countries 1964-2003 followed up to the end of 2006. Acta Oncol. 2010 Jun;49(5):578-607.

[40] Karim-Kos HE, Kiemeney LA, Louwman MW, Coebergh JW, de Vries E. Progress against cancer in the netherlands since the late 1980s: An epidemiological evaluation. Int J Cancer. 2012 Jun 15;130(12):2981-9.

[41] Demetri GD. Identification and treatment of chemoresistant inoperable or metastatic GIST: experience with the selective tyrosine kinase inhibitor imatinib mesylate (STI571). Eur J Cancer 2002;38 Suppl 5:S52-9.

[42] Goodman MT, Matsuno RK, Shvetsov YB. Racial and ethnic variation in the incidence of small-bowel cancer subtypes in the United States, 1995-2008. Dis Colon Rectum 2013;56:441-8. doi:10.1097/DCR.0b013e31826b9d0a.

[43] Andersen MR, Storm HH, Eurocourse Work Package 2 Group. Cancer registration, public health and the reform of the European data protection framework: Abandoning or improving european public health research? Eur J Cancer. 2015 Jun;51(9):1028-38.

[44] Robinson D, Sankila R, Hakulinen T, Moller H. Interpreting international comparisons of cancer survival: The effects of incomplete registration and the presence of death certificate only cases on survival estimates. Eur J Cancer. 2007 Mar;43(5):909-13. 
[45] Baili P, Di Salvo F, Marcos-Gragera R, Siesling S, Mallone S et al. Survival for all cancer patients diagnosed between 1999 and 2007 in Europe: results of EUROCARE5, a population-based study. Eur J Cancer 2015. 
Table 1: Number of cases, percentage Death Certificate Only (DCO) cases and mean age at diagnosis (years) for oesophageal, stomach and small intestine cancers by country/region before exclusion of autopsy and DCO cases.

\begin{tabular}{|c|c|c|c|c|c|c|c|c|c|c|c|c|c|c|c|}
\hline & \multicolumn{5}{|c|}{ Oesophagus } & \multicolumn{5}{|c|}{ Stomach } & \multicolumn{5}{|c|}{ Small Intestine } \\
\hline & $\begin{array}{c}\text { All } \\
\text { cases }\end{array}$ & Men & Women & $\begin{array}{c}\% \\
\mathrm{DCO}^{\mathrm{a}}\end{array}$ & $\begin{array}{l}\text { Mean } \\
\text { age }\end{array}$ & $\begin{array}{c}\text { All } \\
\text { cases }\end{array}$ & Men & Women & $\begin{array}{c}\% \\
\mathrm{DCO}^{\mathrm{a}}\end{array}$ & $\begin{array}{l}\text { Mean } \\
\text { age }\end{array}$ & $\begin{array}{c}\text { All } \\
\text { cases }\end{array}$ & Men & Women & $\begin{array}{c}\% \\
\mathrm{DCO}^{\mathrm{a}}\end{array}$ & $\begin{array}{l}\text { Mean } \\
\text { age }\end{array}$ \\
\hline Northern EU & & & & & & & & & & & & & & & \\
\hline Denmark & 3,177 & 2,242 & 935 & 0 & 68.2 & 4,200 & 2,700 & 1,500 & 0 & 68.7 & 602 & 303 & 299 & 0 & 66.7 \\
\hline Finland & 1,859 & 1,218 & 641 & 1.1 & 69.2 & 5,812 & 3,213 & 2,599 & 0.7 & 70.1 & 691 & 367 & 324 & 1.4 & 65.3 \\
\hline Iceland & 121 & 87 & 34 & 0 & 71.6 & 281 & 171 & 110 & 0 & 72.5 & 47 & 27 & 20 & 0 & 66.2 \\
\hline Norway & 1,466 & 1,041 & 425 & 0.8 & 70.1 & 4,521 & 2,717 & 1,804 & 0.6 & 72.5 & 836 & 441 & 395 & 0.2 & 66.9 \\
\hline $\begin{array}{l}\text { Sweden } \\
\text { Ireland and } \mathbf{U}\end{array}$ & 3,203 & 2,300 & 903 & 0 & 70.1 & 7,863 & 4,740 & 3,123 & 0 & 72.1 & 1,819 & 1,012 & 807 & 0 & 68.9 \\
\hline Ireland & 2,706 & 1,707 & 999 & 0.8 & 69.7 & 3,701 & 2,297 & 1,404 & 1.6 & 69.8 & 392 & 228 & 164 & 1.5 & 65.3 \\
\hline $\begin{array}{l}\text { UK-England } \\
\text { UK-Northern }\end{array}$ & 50,610 & 32,299 & 18,311 & 2.6 & 71.5 & 55,973 & 36,023 & 19,950 & 3.5 & 72.9 & 5,501 & 2,985 & 2,516 & 2.5 & 68.1 \\
\hline Ireland & 1,294 & 817 & 477 & 0.7 & 69.9 & 1,882 & 1,129 & 753 & 1.3 & 71.5 & 189 & 109 & 80 & 1.1 & 65.7 \\
\hline
\end{tabular}




\begin{tabular}{|c|c|c|c|c|c|c|c|c|c|c|c|c|c|c|c|}
\hline UK-Scotland & 6,531 & 4,072 & 2,459 & 0.4 & 70.7 & 6,771 & 4,096 & 2,675 & 0.5 & 72.0 & 615 & 313 & 302 & 0.2 & 67.5 \\
\hline UK-Wales & 3,530 & 2,196 & 1,334 & 2.4 & 71.2 & 4,324 & 2,706 & 1,618 & 3.8 & 73.1 & 413 & 210 & 203 & 1.9 & 68.2 \\
\hline \multicolumn{16}{|l|}{ Central EU } \\
\hline Austria & 2,569 & 2,066 & 503 & 0 & 64.7 & 10,572 & 5,817 & 4,755 & 0 & 71.1 & 889 & 463 & 426 & 0 & 66.2 \\
\hline Belgium $^{b}$ & 3,984 & 3,054 & 930 & 0 & 66.3 & 6,737 & 4,146 & 2,591 & 0 & 71.6 & 856 & 457 & 399 & 0 & 66.6 \\
\hline France $^{b}$ & 4,531 & 3,817 & 714 & 0 & 65.9 & 6,194 & 3,961 & 2,233 & 0 & 71.3 & 822 & 462 & 360 & 0 & 66.8 \\
\hline Germany $^{\mathrm{b}}$ & 10,152 & 8,021 & 2,131 & 10.6 & 65.3 & 31,664 & 17,865 & 13,799 & 15.6 & 70.9 & 2,357 & 1,254 & 1,103 & 8.2 & 66.4 \\
\hline Switzerland ${ }^{\mathrm{b}}$ & 1,222 & 936 & 286 & 1.0 & 68.0 & 2,223 & 1,317 & 906 & 1.7 & 70.3 & 381 & 213 & 168 & 0 & 68.1 \\
\hline The Netherlands & 11,654 & 8,355 & 3,299 & 0 & 67.6 & 16,208 & 10,268 & 5,940 & 0 & 69.9 & 1,769 & 920 & 849 & 0 & 66.0 \\
\hline \multicolumn{16}{|l|}{ Southern EU } \\
\hline Croatia & 1,815 & 1,492 & 323 & 7.6 & 64.9 & 9,146 & 5,553 & 3,593 & 8.2 & 68.6 & 306 & 173 & 133 & 6.5 & 66.1 \\
\hline Italy $^{\mathrm{b}}$ & 5,600 & 4,178 & 1,422 & 1.5 & 68.9 & 36,113 & 20,960 & 15,153 & 1.6 & 72.6 & 2,248 & 1,259 & 989 & 1.2 & 68.6 \\
\hline Malta & 94 & 69 & 25 & 8.5 & 68.2 & 359 & 216 & 143 & 5.0 & 70.0 & 31 & 13 & 18 & 3.2 & 60.5 \\
\hline Portugal $^{\mathrm{b}}$ & 2,619 & 2,201 & 418 & 0.1 & 63.7 & 14,723 & 8,931 & 5,792 & 0.1 & 67.2 & 641 & 366 & 275 & 0 & 66.3 \\
\hline Slovenia & 739 & 607 & 132 & 2.3 & 64.9 & 3,772 & 2,314 & 1,458 & 2.4 & 68.9 & 162 & 95 & 67 & 0 & 65.1 \\
\hline Spain $^{\mathrm{b}}$ & 1,782 & 1,541 & 241 & 2.6 & 65.1 & 6,598 & 4,193 & 2,405 & 3.6 & 70.4 & 378 & 225 & 153 & 1.3 & 67.2 \\
\hline Eastern EU & & & & & & & & & & & & & & & \\
\hline
\end{tabular}




\begin{tabular}{|c|c|c|c|c|c|c|c|c|c|c|c|c|c|c|c|}
\hline Bulgaria & 1,478 & 1,152 & 326 & 22.5 & 64.6 & 14,616 & 9,005 & 5,611 & 20.5 & 68.2 & 345 & 197 & 148 & 24.1 & 63.5 \\
\hline Czech Republic & 3,680 & 3,090 & 590 & 5.1 & 63.6 & 13,760 & 7,996 & 5,764 & 4.6 & 69.3 & 1,019 & 559 & 460 & 3.9 & 65.4 \\
\hline Estonia & 434 & 355 & 79 & 0 & 64.9 & 3,277 & 1,776 & 1,501 & 0.2 & 66.8 & 90 & 36 & 54 & 0 & 64.2 \\
\hline Latvia & 881 & 739 & 142 & 6.5 & 63.8 & 5,324 & 2,948 & 2,376 & 6.6 & 67.0 & 114 & 52 & 62 & 11.4 & 65.8 \\
\hline Lithuania & 1,180 & 1,022 & 158 & 4.8 & 63.1 & 7,047 & 4,095 & 2,952 & 4.2 & 67.2 & 176 & 83 & 93 & 8.5 & 65.8 \\
\hline Poland ${ }^{b}$ & 1,353 & 1,070 & 283 & 1.7 & 63.5 & 6,253 & 3,938 & 2,315 & 1.6 & 67.0 & 230 & 122 & 108 & 0 & 64.3 \\
\hline Slovakia & 1,937 & 1,732 & 205 & 12.5 & 60.7 & 6,826 & 4,111 & 2,715 & 12.3 & 618.1 & 397 & 212 & 185 & 10.8 & 64.3 \\
\hline
\end{tabular}

a Also includes 'autopsy-only' basis of diagnosis. ${ }^{\text {b }}$ Pooled rates as these countries did not have national coverage. 
Table 2: Five-year relative survival (RS) and corresponding 95\% confidence interval (CI) of oesophageal cancer in three periods (19992001, 2002-2004, 2005-2007) by country, European region and European average, with p-values of differences ${ }^{\mathrm{a}}$ between periods.

\begin{tabular}{|c|c|c|c|c|c|c|c|c|c|}
\hline \multirow{3}{*}{$\begin{array}{l}\text { Europe } \\
\end{array}$} & \multirow{3}{*}{$\begin{array}{l}\text { Number of cases } \\
\text { analysed across } \\
\text { all time periods } \\
111006\end{array}$} & \multicolumn{2}{|c|}{ 1999-2001 } & \multicolumn{2}{|c|}{ 2002-2004 } & \multicolumn{2}{|c|}{ 2005-2007 } & \multicolumn{2}{|c|}{$\begin{array}{r}\text { 2005-2007 } \\
\text { Vs 1999-2001 }\end{array}$} \\
\hline & & $\% \mathrm{RS}$ & $95 \% \mathrm{CI}$ & $\% \mathrm{RS}$ & $95 \% \mathrm{CI}$ & $\% \mathbf{R S}$ & $95 \% \mathrm{CI}$ & Abs diff & p-value \\
\hline & & 9.9 & $(9.3-10.5)$ & 11.7 & $(11.0-12.3)$ & 12.6 & $(12.0-13.2)$ & 2.7 & $<0.001$ \\
\hline Northern EU & 10471 & 9.1 & $(8.0-10.4)$ & 11.3 & $(10.1-12.8)$ & 10.8 & $(9.7-12.1)$ & 1.7 & 0.023 \\
\hline Denmark & 3401 & 4.6 & $(3.3-6.4)$ & 9.0 & $(7.0-11.5)$ & 9.7 & $(7.9-11.8)$ & 5.1 & $<0.001$ \\
\hline Finland & 1959 & 9.6 & $(7.2-12.7)$ & 12.9 & $(9.9-16.7)$ & 12.1 & $(9.5-15.2)$ & 2.5 & 0.108 \\
\hline Iceland $^{\mathrm{b}}$ & 129 & - & & - & - & - & - & - & - \\
\hline Norway & 1572 & 8.4 & $(5.7-12.4)$ & 12.5 & $(9.5-16.5)$ & 10.9 & $(8.0-14.8)$ & 2.5 & 0.150 \\
\hline Sweden & 3411 & 13.3 & $(11.0-16.0)$ & 12.3 & $(10.0-15.2)$ & 10.6 & $(8.8-12.8)$ & 2.7 & 0.052 \\
\hline Ireland and UK & 67862 & 10.3 & $(9.8-10.8)$ & 11.9 & (11.4-12.4) & 13.5 & $(13.0-14.1)$ & 3.2 & $<0.001$ \\
\hline Ireland & 2816 & 11.9 & $(9.6-14.7)$ & 15.3 & $(12.7-18.3)$ & 16.7 & $(14.2-19.6)$ & 4.8 & 0.005 \\
\hline England & 52786 & 9.9 & $(9.4-10.6)$ & 11.5 & $(10.9-12.1)$ & 13.7 & $(13.1-14.3)$ & 3.7 & $<0.001$ \\
\hline
\end{tabular}




\begin{tabular}{|c|c|c|c|c|c|c|c|c|c|}
\hline Northern Ireland ${ }^{\mathrm{b}}$ & 1389 & 9.6 & $(7.1-13.0)$ & 14.6 & $(11.3-18.7)$ & - & - & - & - \\
\hline Wales & 3727 & 14.1 & $(11.7-17.1)$ & 13.8 & $(11.6-16.4)$ & 12.6 & $(10.5-15.0)$ & 1.6 & 0.188 \\
\hline Central EU & 18139 & 10.8 & $(9.9-11.8)$ & 13.9 & $(12.8-15.0)$ & 15.2 & $(14.2-16.2)$ & 4.3 & $<0.001$ \\
\hline Austria & 2711 & 11.7 & $(9.4-14.6)$ & 17.9 & $(15.1-21.2)$ & 17.1 & $(14.6-20.0)$ & 5.4 & 0.002 \\
\hline Germany $^{b}$ & 1804 & 16.1 & $(12.8-20.4)$ & 13.7 & $(10.6-17.7)$ & - & - & - & - \\
\hline Switzerland & 1075 & 15.3 & $(11.4-20.5)$ & 18.3 & $(14.3-23.4)$ & 18.9 & $(14.6-24.4)$ & 3.6 & 0.145 \\
\hline The Netherlands & 11744 & 9.6 & $(8.6-10.8)$ & 13.1 & $(11.9-14.5)$ & 14.4 & $(13.3-15.7)$ & 4.8 & $<0.001$ \\
\hline Malta $^{b}$ & 67 & - & - & - & - & - & - & - & - \\
\hline Slovenia $^{b}$ & 805 & 7.1 & $(4.2-12.1)$ & - & - & 8.6 & $(5.5-13.6)$ & 1.5 & 0.289 \\
\hline Spain & 1792 & 7.9 & $(6.1-10.2)$ & 7.9 & $(6.1-10.2)$ & - & - & - & - \\
\hline Eastern EU & 10063 & 7.3 & $(6.1-8.6)$ & 7.4 & $(6.3-8.6)$ & 8.1 & (7.0-9.3) & 0.8 & 0.175 \\
\hline Bulgaria $^{b}$ & 1172 & - & - & - & - & 6.7 & $(4.2-10.7)$ & - & - \\
\hline
\end{tabular}




\begin{tabular}{|l|r|rr|rr|rr} 
Czech Republic & 3496 & 7.3 & $(5.4-9.8)$ & 9.2 & $(7.0-12.2)$ & 11.4 & $(9.5-13.7)$ \\
Estonia $^{\mathrm{b}}$ & 485 & - & - & - & - & -1.2 & 0.003 \\
Lithuania $^{\mathrm{b}}$ & 1348 & 8.4 & $(5.6-12.5)$ & 4.7 & $(2.9-7.5)$ & - & - \\
Poland $^{\mathrm{b}}$ & 1474 & 8.1 & $(5.3-12.4)$ & 7.7 & $(5.3-11.3)$ & 6.2 & $(4.0-9.7)$ \\
Slovakia $^{\mathrm{b}}$ & 111006 & 6.4 & $(3.9-10.3)$ & 10.1 & $(6.4-15.6)$ & - & - \\
\end{tabular}

Abs $=$ absolute, Diff $=$ Difference.

${ }^{a}$ Survival differences between periods have been assessed by the Z-test.

${ }^{\mathrm{b}}$ Standardized Survival rates could not be calculated where one or more age specific rates are absent due to small number of cases.

Note: $\%$ difference is the relative difference.

Note: Empty fields of RS in France and Spain in 2007 are due to a limitation of analysis to periods 1999-2001 and 2002-2004 only. 
Table 3: Five-year relative survival (RS) and corresponding 95\% confidence interval (CI) of stomach cancer in three periods (1999-2001, 2002-2004, 2005-2007) by country, European region and European average, with p-values of differences ${ }^{\mathrm{a}}$ between periods.

\begin{tabular}{|c|c|c|c|c|c|c|c|c|c|}
\hline & \multirow{2}{*}{$\begin{array}{l}\text { Number of cases } \\
\text { analysed across } \\
\text { all time periods }\end{array}$} & \multicolumn{2}{|c|}{ 1999-2001 } & \multicolumn{2}{|c|}{ 2002-2004 } & \multicolumn{2}{|c|}{ 2005-2007 } & \multicolumn{2}{|c|}{$\begin{array}{c}2005-2007 \\
\text { vs 1999-2001 }\end{array}$} \\
\hline & & $\% \mathrm{RS}$ & $95 \% \mathrm{CI}$ & $\% \mathrm{RS}$ & $95 \% \mathrm{CI}$ & $\% \mathrm{RS}$ & $95 \% \mathrm{CI}$ & Abs diff & p-value \\
\hline Europe & 232452 & 23.3 & $(22.9-23.8)$ & 23.8 & $(23.4-24.3)$ & 25.1 & $(24.6-25.6)$ & 1.8 & $<0.001$ \\
\hline Northern EU & 26201 & 22.4 & (21.4-23.5) & 21.7 & $(20.7-22.7)$ & 22.7 & (21.6-23.8) & 0.3 & 0.360 \\
\hline Denmark & 4691 & 14.0 & $(12.2-16.2)$ & 14.7 & $(12.7-16.9)$ & 18.3 & $(16.3-20.6)$ & 4.3 & 0.002 \\
\hline Finland & 6667 & 28.5 & $(26.5-30.8)$ & 25.0 & $(23.0-27.1)$ & 25.2 & $(23.1-27.5)$ & -3.3 & 0.016 \\
\hline Iceland $^{\mathrm{b}}$ & 341 & - & - & - & - & - & - & - & - \\
\hline Norway & 5341 & 23.5 & $(21.2-26.1)$ & 21.8 & $(19.6-24.3)$ & 23.5 & $(21.1-26.2)$ & 0.0 & 0.499 \\
\hline Sweden & 9152 & 21.4 & $(19.8-23.2)$ & 22.6 & $(20.8-24.5)$ & 22.5 & $(20.7-24.4)$ & 1.0 & 0.214 \\
\hline Ireland and UK & 83908 & 16.1 & $(15.6-16.7)$ & 16.5 & $(16.0-17.1)$ & 18.2 & (17.6-18.8) & 2.0 & $<0.001$ \\
\hline Ireland & 4056 & 19.4 & $(17.1-22.0)$ & 19.4 & $(17.0-22.0)$ & 21.9 & (19.4-24.6) & 2.5 & 0.086 \\
\hline England & 64533 & 16.1 & $(15.5-16.7)$ & 16.3 & $(15.7-16.9)$ & 18.0 & $(17.3-18.7)$ & 1.9 & $<0.001$ \\
\hline
\end{tabular}




\begin{tabular}{|c|c|c|c|c|c|c|c|c|c|}
\hline Northern Ireland & 2189 & 17.7 & $(14.7-21.4)$ & 18.8 & $(15.8-22.4)$ & 18.4 & $(15.0-22.5)$ & 0.6 & 0.400 \\
\hline Scotland & 7992 & 14.7 & $(13.1-16.5)$ & 16.8 & $(15.1-18.7)$ & 16.3 & $(14.5-18.3)$ & 1.6 & 0.104 \\
\hline Wales & 5144 & 16.1 & $(13.9-18.6)$ & 16.5 & $(14.3-18.9)$ & 20.0 & $(17.5-22.9)$ & 4.0 & 0.015 \\
\hline Central EU & 39365 & 24.0 & $(23.2-24.9)$ & 24.7 & $(23.9-25.6)$ & 26.2 & $(25.3-27.1)$ & 2.1 & $<0.001$ \\
\hline Austria & 12740 & 30.7 & $(29.1-32.3)$ & 29.8 & $(28.2-31.5)$ & 33.6 & $(31.8-35.4)$ & 2.9 & 0.009 \\
\hline France $^{\mathrm{b}}$ & 4997 & 25.4 & $(23.4-27.5)$ & 28.1 & $(26.1-30.3)$ & - & - & & - \\
\hline Germany & 4486 & 27.2 & $(24.7-30.0)$ & 27.0 & $(24.5-29.7)$ & 27.5 & $(24.9-30.3)$ & 0.3 & 0.439 \\
\hline Switzerland & 2019 & 25.0 & $(21.6-29.0)$ & 29.3 & $(25.5-33.7)$ & 31.4 & $(27.4-36.0)$ & 6.4 & 0.014 \\
\hline The Netherlands & 18808 & 18.9 & $(17.8-20.1)$ & 20.6 & (19.4-21.8) & 21.1 & $(19.9-22.3)$ & 2.2 & 0.005 \\
\hline Southern EU & 29234 & 30.5 & (29.4-31.6) & 30.4 & (29.4-31.5) & 32.1 & $(31.0-33.3)$ & 1.6 & 0.021 \\
\hline Italy pool & 23784 & 32.7 & $(31.5-34.0)$ & 31.6 & $(30.4-32.9)$ & 33.8 & $(32.5-35.1)$ & 1.1 & 0.126 \\
\hline Malta $^{b}$ & 398 & - & - & - & - & - & - & - & - \\
\hline Slovenia & 4116 & 20.8 & $(18.5-23.5)$ & 27.1 & $(24.4-30.1)$ & 27.9 & $(25.3-30.7)$ & 7.0 & $<0.001$ \\
\hline Spain & 6569 & 25.1 & $(23.5-26.8)$ & 25.9 & $(24.2-27.7)$ & - & & - & - \\
\hline Eastern EU & 53747 & 17.6 & (16.9-18.2) & 19.0 & (18.3-19.6) & 18.8 & (18.2-19.5) & 1.3 & 0.004 \\
\hline Bulgaria & 12555 & 10.9 & $(9.8-12.1)$ & 12.5 & $(11.3-13.8)$ & 12.8 & $(11.7-14.0)$ & 2.0 & 0.010 \\
\hline
\end{tabular}




\begin{tabular}{|c|c|c|c|c|c|c|c|c|c|}
\hline Czech Republic & 14449 & 18.1 & $(16.9-19.4)$ & 21.3 & (19.9-22.7) & 22.6 & $(21.2-24.0)$ & 4.4 & $<0.001$ \\
\hline Estonia & 3852 & 21.8 & $(19.3-24.7)$ & 24.8 & $(22.0-27.8)$ & 22.2 & $(19.6-25.1)$ & 0.3 & 0.432 \\
\hline Lithuania & 8614 & 22.0 & $(20.4-23.8)$ & 23.4 & $(21.7-25.2)$ & 23.7 & $(21.7-25.8)$ & 1.7 & 0.112 \\
\hline Poland & 7164 & 15.2 & $(13.5-17.0)$ & 16.7 & $(15.0-28.5)$ & 15.6 & $(14.0-17.4)$ & 0.4 & 0.367 \\
\hline Slovakia & 7186 & 21.2 & $(19.3-23.2)$ & 20.3 & $(18.6-22.3)$ & 21.1 & $(19.2-23.1)$ & -0.1 & 0.471 \\
\hline
\end{tabular}

Abs = absolute, Diff $=$ Difference.

${ }^{a}$ Survival differences between periods have been assessed by the Z-test.

${ }^{\mathrm{b}}$ Standardized Survival rates could not be calculated where one or more age specific rates are absent due to small number of cases.

Note: $\%$ difference is the relative difference.

Note: Empty fields of RS in Spain in 2007 are due to a limitation of analysis to periods 1999-2001 and 2002-2004 only. 
Table 4: Age-standardised 1-year, 5-year relative survival, and 5-year relative survival conditional on surviving 1 year, with $95 \%$ confidence intervals, for cardia and non-cardia stomach cancers.

\begin{tabular}{|c|c|c|c|c|c|c|c|c|c|c|c|c|c|c|}
\hline & \multicolumn{7}{|c|}{ Cardia } & \multicolumn{7}{|c|}{ Non-cardia } \\
\hline & \multirow{2}{*}{$\begin{array}{l}\text { No. of } \\
\text { cases }\end{array}$} & \multicolumn{2}{|c|}{ 1-year } & \multicolumn{2}{|c|}{ 5-year } & \multicolumn{2}{|c|}{ Conditional } & \multirow{2}{*}{$\begin{array}{l}\text { No. of } \\
\text { cases }\end{array}$} & \multicolumn{2}{|c|}{ 1-year } & \multicolumn{2}{|c|}{ 5-year } & \multicolumn{2}{|c|}{ Conditional } \\
\hline & & $\% \mathrm{RS}$ & $95 \% \mathrm{CI}$ & $\% \mathrm{RS}$ & $95 \% \mathrm{CI}$ & $\% \mathrm{RS}$ & $95 \% \mathrm{CI}$ & & $\% \mathrm{RS}$ & $95 \% \mathrm{CI}$ & $\% \mathrm{RS}$ & $95 \% \mathrm{CI}$ & $\% \mathrm{RS}$ & $95 \% \mathrm{CI}$ \\
\hline Europe & 48611 & 46.0 & $45.5-46.4$ & 16.0 & $15.5-16.4$ & 34.0 & $33.2-34.9$ & 96020 & 54.6 & 54.3-54.9 & 30.5 & 30.1-30.9 & 66.3 & 65.9-66.8 \\
\hline Northern EU & 5299 & 43.3 & 41.9-44.7 & 14.1 & $12.9-15.3$ & 32.5 & $30.0-35.1$ & 6027 & 55.2 & 53.8-56.5 & 28.6 & 27.1-30.2 & 51.9 & 49.4-54.5 \\
\hline Denmark & 1687 & 41.0 & $38.6-43.4$ & 12.8 & $10.8-15.0$ & 31.2 & $26.8-36.2$ & 1149 & 48.0 & $44.9-51.0$ & 25.9 & $22.8-29.2$ & 53.9 & $48.4-60.1$ \\
\hline Finland & 936 & 45.9 & $42.5-49.2$ & 16.0 & $13.2-19.1$ & 34.9 & $29.5-41.4$ & 272 & 57.8 & $51.3-63.7$ & - & - & - & - \\
\hline Iceland & 41 & 31.0 & $18.0-44.8$ & 10.3 & $3.4-19.1$ & 33.2 & $15.2-72.5$ & 70 & 74.7 & $62.7-83.0$ & - & - & - & - \\
\hline Norway & 967 & 43.9 & $40.6-47.1$ & 15.4 & $12.7-18.5$ & 35.2 & $29.6-42.0$ & 1831 & 58.0 & $55.4-60.5$ & 30.0 & $27.2-32.9$ & 51.8 & $47.7-56.2$ \\
\hline Sweden & 1668 & 44.2 & $41.7-46.6$ & 13.6 & $11.6-15.7$ & 30.7 & $26.6-35.5$ & 2705 & 55.9 & $53.7-58.0$ & 28.0 & $25.6-30.4$ & 50.1 & $46.3-54.1$ \\
\hline Ireland and UK & 19244 & 46.6 & $45.8-47.3$ & 14.4 & 13.8-15.1 & 31.0 & 29.7-32.4 & 17457 & 48.4 & 47.5-49.3 & 23.2 & 22.3-24.0 & 47.9 & 46.3-49.5 \\
\hline Ireland & 986 & 42.2 & $39.0-45.3$ & 17.0 & $14.1-20.0$ & 40.2 & $34.3-47.1$ & 1705 & 46.2 & $43.8-48.7$ & 24.4 & $21.9-27.0$ & 52.8 & $48.3-57.7$ \\
\hline England & 14510 & 47.4 & $46.5-48.2$ & 14.8 & $14.1-15.5$ & 31.2 & $29.8-32.70$ & 11932 & 49.2 & $48.1-50.3$ & 23.1 & $22.0-24.2$ & 46.9 & $45.1-48.9$ \\
\hline Northern Ireland & 462 & 46.4 & $41.6-51.1$ & 16.2 & $12.3-20.7$ & 35.0 & $27.5-44.5$ & 534 & 42.2 & $37.4-47.0$ & 21.2 & $16.9-25.8$ & 50.1 & $41.9-59.9$ \\
\hline Scotland & 1983 & 42.9 & $40.5-45.3$ & 11.3 & $9.6-13.2$ & 26.4 & $22.7-30.7$ & 1787 & 47.6 & $44.9-50.2$ & 23.4 & $20.8-26.1$ & 49.2 & $44.6-54.4$ \\
\hline Wales & 1303 & 46.7 & $43.8-49.6$ & 13.2 & $10.9-15.8$ & 28.4 & $23.8-33.8$ & 1499 & 47.3 & $44.2-50.4$ & 22.3 & $19.4-25.4$ & 47.2 & $41.9-53.1$ \\
\hline Central EU & 13230 & 49.2 & 48.4-50.1 & 18.2 & 17.4-19.0 & 37.0 & 35.4-38.5 & 26709 & 60.9 & $60.3-61.5$ & 36.0 & $35.2-36.7$ & 59.1 & 58.0-60.1 \\
\hline Austria & 1297 & 50.5 & $47.7-53.3$ & 22.6 & $19.8-25.5$ & 44.7 & $39.9-50.1$ & 1895 & 65.9 & $63.5-68.1$ & 40.2 & $37.3-43.1$ & 61.0 & $57.3-65.0$ \\
\hline Belgium & 1264 & 55.9 & $53.1-58.7$ & 20.5 & $17.7-23.5$ & 36.7 & $32.1-41.9$ & 1504 & 63.0 & $60.3-65.7$ & 35.6 & $32.3-38.8$ & 56.4 & $52.0-61.2$ \\
\hline
\end{tabular}




\begin{tabular}{|c|c|c|c|c|c|c|c|c|c|c|c|c|c|c|}
\hline France & 1384 & 50.6 & $47.9-53.3$ & 14.7 & $12.6-17.0$ & 29.0 & $25.3-33.4$ & 2949 & 58.6 & $56.6-60.6$ & 32.8 & $30.6-35.0$ & 56.0 & $52.9-59.2$ \\
\hline Germany & 4506 & 52.7 & $51.2-54.2$ & 22.3 & $20.7-23.9$ & 42.3 & $39.7-45.1$ & 11906 & 64.4 & $63.5-65.3$ & 40.1 & $39.0-41.3$ & 62.3 & $60.8-63.9$ \\
\hline Switzerland & 494 & 52.0 & $47.4-56.5$ & - & - & - & - & 1145 & 64.1 & $61.1-67.0$ & 40.8 & $37.2-44.3$ & 63.6 & $59.1-68.4$ \\
\hline The Netherlands & 4285 & 42.4 & $40.9-43.9$ & 13.1 & $11.9-14.5$ & 31.0 & $28.3-34.0$ & 7310 & 53.7 & $52.5-54.9$ & 28.9 & $27.5-30.2$ & 53.8 & $51.6-56.0$ \\
\hline Croatia & 476 & 42.43 & $37.7-47.1$ & 27.0 & 21.9-32.4 & 63.7 & $54.2-74.9$ & 446 & 56.6 & 51.6-61.4 & 37.4 & $31.4-43.5$ & 66.1 & $57.6-75.8$ \\
\hline Southern EU & 5793 & 48.6 & 47.2-49.9 & 20.2 & $18.9-21.5$ & 41.5 & $39.2-44.0$ & 24960 & 60.1 & $59.4-60.7$ & 36.2 & $35.5-36.9$ & 60.2 & $59.2-61.3$ \\
\hline Italy & 3193 & 52.2 & $50.3-54.0$ & 20.9 & $19.1-22.7$ & 40.0 & $37.0-43.3$ & 15728 & 61.3 & $60.5-62.1$ & 37.1 & $36.2-38.1$ & 60.6 & $59.2-61.9$ \\
\hline Malta & 65 & 35.9 & $25.5-46.4$ & - & - & - & - & 107 & 49.2 & $38.8-58.7$ & 25.4 & $16.9-34.8$ & 51.7 & $38.6-69.3$ \\
\hline Portugal & 890 & 45.5 & $42.0-48.9$ & 20.6 & $17.6-23.9$ & 45.4 & $39.7-51.9$ & 4188 & 59.4 & $57.8-60.9$ & 36.1 & $34.4-37.9$ & 60.8 & $58.4-63.4$ \\
\hline Slovenia & 473 & 46.2 & $41.4-50.8$ & 18.3 & $14.1-22.9$ & 39.6 & $31.8-49.3$ & 1424 & 61.2 & $58.6-63.8$ & 41.0 & $37.8-44.2$ & 67.0 & $62.8-71.5$ \\
\hline Spain & 696 & 44.7 & $40.8-48.5$ & 16.9 & $13.9-20.2$ & 37.9 & $32.0-44.8$ & 3067 & 55.4 & $53.5-57.2$ & 30.8 & $28.9-32.7$ & 55.6 & $52.7-58.5$ \\
\hline Eastern EU & 5045 & 36.4 & 35.1-37.8 & 13.1 & $12.0-14.4$ & 36.1 & $33.2-39.2$ & 20867 & 45.6 & 44.9-46.3 & 23.7 & $23.0-24.4$ & 52.0 & 50.6-53.4 \\
\hline Bulgaria & 1273 & 25.3 & $22.9-27.8$ & 7.6 & 5.8-9.9 & 30.2 & $23.5-38.7$ & 6460 & 33.8 & $32.6-35.0$ & 14.2 & $13.1-15.4$ & 42.0 & $39.1-45.2$ \\
\hline Czech Republic & 1596 & 41.4 & $38.9-43.9$ & 15.6 & 13.4-18.0 & 37.7 & $32.9-43.2$ & 5927 & 49.5 & $48.2-50.9$ & 27.5 & $26.0-29.0$ & 55.5 & $53.0-58.1$ \\
\hline Estonia & 262 & 41.2 & $35.0-47.3$ & 18.4 & $12.9-24.7$ & 44.7 & $33.6-59.3$ & 1760 & 50.9 & $48.4-53.2$ & 29.1 & $26.3-31.8$ & 57.2 & $52.7-62.0$ \\
\hline Latvia & 266 & 32.8 & $27.0-38.7$ & 15.9 & $10.8-21.9$ & 48.4 & $35.8-65.5$ & 1012 & 44.1 & $40.9-47.3$ & 22.8 & $19.4-26.3$ & 51.7 & $45.2-59.0$ \\
\hline Lithuania & 312 & 42.2 & $36.3-47.9$ & 15.4 & $11.2-20.3$ & 36.6 & $28.0-47.6$ & 2218 & 54.6 & $52.4-56.7$ & 31.3 & $28.8-33.7$ & 57.3 & $53.5-61.3$ \\
\hline Poland & 627 & 41.6 & $37.7-45.5$ & 12.8 & $9.6-16.5$ & 30.8 & $23.9-39.6$ & 398 & 47.9 & $42.8-52.9$ & 17.4 & $12.6-22.9$ & 36.4 & $27.5-48.1$ \\
\hline Slovakia & 709 & 38.9 & $35.1-42.7$ & 13.6 & $10.5-17.0$ & 34.8 & $28.0-43.3$ & 3092 & 53.9 & $52.0-55.7$ & 28.7 & $26.7-30.7$ & 53.2 & $50.1-56.5$ \\
\hline
\end{tabular}


Table 5: Five-year relative survival (RS) and corresponding 95\% confidence interval (CI) of small intestine cancer in three periods (19992001, 2002-2004, 2005-2007) by country, European region and European average, with p-values of differences* between periods.

\begin{tabular}{|c|c|c|c|c|c|c|c|c|c|}
\hline & \multirow{2}{*}{$\begin{array}{l}\text { Number of cases } \\
\text { analysed across } \\
\text { all time periods }\end{array}$} & \multicolumn{2}{|c|}{ 1999-2001 } & \multicolumn{2}{|c|}{ 2002-2004 } & \multicolumn{2}{|c|}{ 2005-2007 } & \multicolumn{2}{|c|}{$\begin{array}{c}2005-2007 \\
\text { vs 1999-2001 }\end{array}$} \\
\hline & & $\% \mathbf{R S}$ & $95 \% \mathrm{CI}$ & $\% \mathrm{RS}$ & $95 \% \mathrm{CI}$ & $\% \mathrm{RS}$ & $95 \%$ CI & Abs diff & p-value \\
\hline Europe & 18116 & 40.5 & $(38.5-42.7)$ & 45.8 & (43.9-47.9) & 48.7 & (46.9-50.5) & 8.1 & $<0.001$ \\
\hline Northern EU & 4021 & 49.9 & $(46.7-53.3)$ & 50.7 & $(47.7-53.9)$ & 55.8 & $(53.0-58.8)$ & 6.0 & 0.004 \\
\hline Denmark & 626 & 37.4 & $(30.3-46.1)$ & 37.7 & $(30.4-46.6)$ & 39.6 & $(33.2-47.1)$ & 2.2 & 0.341 \\
\hline Finland & 678 & 51.7 & $(43.7-61.2)$ & 55.4 & $(48.8-62.9)$ & 62.1 & $(54.9-70.3)$ & 10.4 & 0.040 \\
\hline Iceland $^{\mathrm{b}}$ & 49 & - & - & - & - & - & - & - & - \\
\hline Norway & 834 & 52.6 & $(45.7-60.6)$ & 51.6 & $(45.4-58.6)$ & 56.6 & $(50.5-63.3)$ & 3.9 & 0.216 \\
\hline Sweden & 1835 & 52.0 & $(47.5-57.0)$ & 53.3 & $(48.9-58.1)$ & 59.5 & $(55.3-64.0)$ & 7.5 & 0.011 \\
\hline Ireland and UK & 7178 & 35.3 & (33.1-37.6) & 36.1 & $(34.1-38.3)$ & 37.7 & $(35.7-39.8)$ & 2.4 & 0.058 \\
\hline Ireland & 376 & 35.5 & $(26.2-48.1)$ & 44.7 & $(36.3-55.2)$ & 42.8 & $(34.7-52.9)$ & 7.3 & 0.154 \\
\hline England & 5539 & 34.4 & $(31.9-37.0)$ & 35.1 & $(32.8-37.5)$ & 37.7 & $(35.5-40.2)$ & 3.4 & 0.027 \\
\hline
\end{tabular}




\begin{tabular}{|c|c|c|c|c|c|c|c|c|c|}
\hline Northern Ireland & 230 & 37.4 & $(27.9-50.2)$ & 33.9 & $(23.0-50.0)$ & 43.5 & $(30.6-61.9)$ & 6.1 & 0.263 \\
\hline Scotland & 639 & 39.6 & $(32.7-48.0)$ & 37.5 & $(30.1-46.7)$ & 38.4 & $(31.9-46.1)$ & -1.3 & 0.405 \\
\hline Wales & 401 & 38.9 & $(28.6-52.7)$ & 38.2 & $(29.6-49.3)$ & 33.3 & $(25.9-42.8)$ & -5.6 & 0.227 \\
\hline Central EU & 3399 & 44.1 & (40.7-47.8) & 47.8 & $(44.5-51.2)$ & $\mathbf{5 3 . 0}$ & $(50.0-56.3)$ & 9.0 & $<0.001$ \\
\hline Austria & 899 & 43.6 & $(37.3-50.9)$ & 52.3 & $(46.0-59.4)$ & 55.7 & $(50.1-61.9)$ & 12.1 & 0.004 \\
\hline France & 572 & 45.3 & $(39.3-52.3)$ & 48.3 & $(42.2-56.2)$ & - & - & - & - \\
\hline Germany & 323 & 42.0 & $(31.6-56.0)$ & 45.6 & $(34.9-59.6)$ & 50.1 & $(41.2-61.0)$ & 8.1 & 0.154 \\
\hline Switzerland & 294 & 54.7 & $(45.0-66.5)$ & 59.9 & $(50.4-71.0)$ & 55.4 & $(45.4-67.5)$ & 0.7 & 0.467 \\
\hline The Netherlands & 1737 & 44.5 & $(39.6-50.0)$ & 43.3 & $(39.0-48.2)$ & 51.5 & $(47.2-56.3)$ & 7.1 & 0.022 \\
\hline Southern EU & 1570 & 39.5 & $(34.7-44.9)$ & 49.0 & $(44.3-54.2)$ & 49.7 & $(45.5-54.3)$ & 10.2 & 0.001 \\
\hline Italy & 1338 & 38.7 & $(33.5-44.6)$ & 48.7 & $(43.7-54.4)$ & 51.1 & $(46.4-56.3)$ & 12.5 & $<0.001$ \\
\hline Malta $^{b}$ & 34 & - & - & - & - & - & - & - & - \\
\hline Slovenia ${ }^{b}$ & 153 & - & - & 48.5 & $(33.8-69.6)$ & - & - & - & - \\
\hline Spain & 347 & 46.3 & $(38.4-56.0)$ & 42.4 & $(35.9-50.1)$ & - & - & - & - \\
\hline Eastern EU & 1951 & 34.5 & $(29.4-40.4)$ & 43.4 & $(38.9-48.4)$ & 43.5 & (39.6-47.8) & 9.1 & 0.005 \\
\hline Bulgaria & 248 & 41.9 & $(26.0-67.6)$ & 35.8 & $(25.1-51.0)$ & - & - & - & - \\
\hline
\end{tabular}




\begin{tabular}{|c|c|c|c|c|c|c|c|c|c|}
\hline Czech Republic & 849 & 35.8 & $(28.3-45.4)$ & 46.1 & (39.4-54.0) & 46.9 & $(41.0-53.6)$ & 11.0 & 0.020 \\
\hline Estonia $^{\mathrm{b}}$ & 95 & - & - & - & - & - & - & - & - \\
\hline Lithuania $^{\mathrm{b}}$ & 186 & - & - & - & - & 32.9 & $(22.0-49.4)$ & - & - \\
\hline Poland ${ }^{b}$ & 225 & - & - & - & - & 44.7 & $(33.7-59.1)$ & - & - \\
\hline Slovakia & 368 & 51.4 & $(39.4-67.1)$ & 42.0 & $(32.2-54.7)$ & 46.2 & $(37.6-56.8)$ & -5.2 & 0.269 \\
\hline
\end{tabular}

Abs $=$ absolute, Diff $=$ Difference.

${ }^{\text {a }}$ Survival differences between periods have been assessed by the Z-test.

${ }^{\mathrm{b}}$ Standardized Survival rates could not be calculated where one or more age specific rates are absent due to small number of cases.

Note: $\%$ difference is the relative difference.

Note: Empty fields of RS in France and Spain in 2007 are due to a limitation of analysis to periods 1999-2001 and 2002-2004 only. 
Supplement 1: Age-standardised 5-year RS for oesophageal cancer in a) Northern Europe, b) UK and Ireland, c) Central Europe, d) Southern Europe, e) Eastern Europe and f) European average.

a)

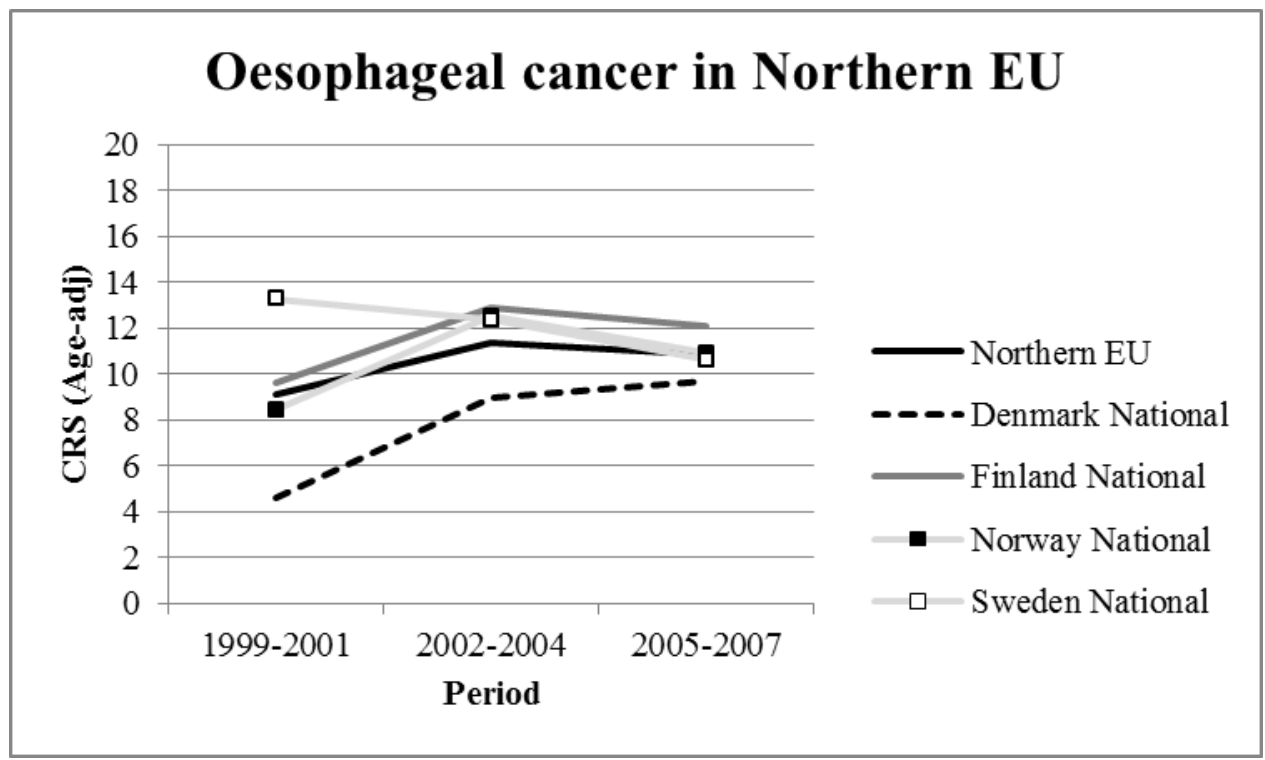

Note: Iceland removed as no points are available due to small number of cases

b)

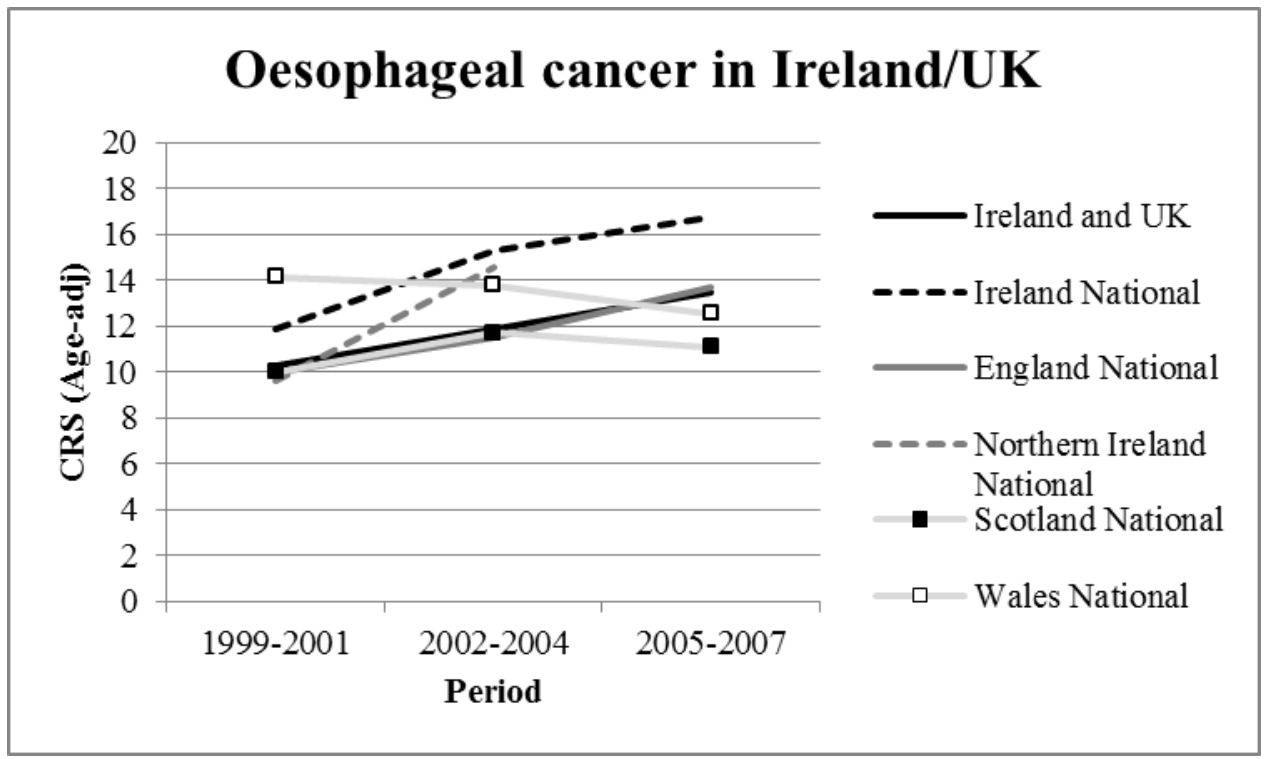


c)

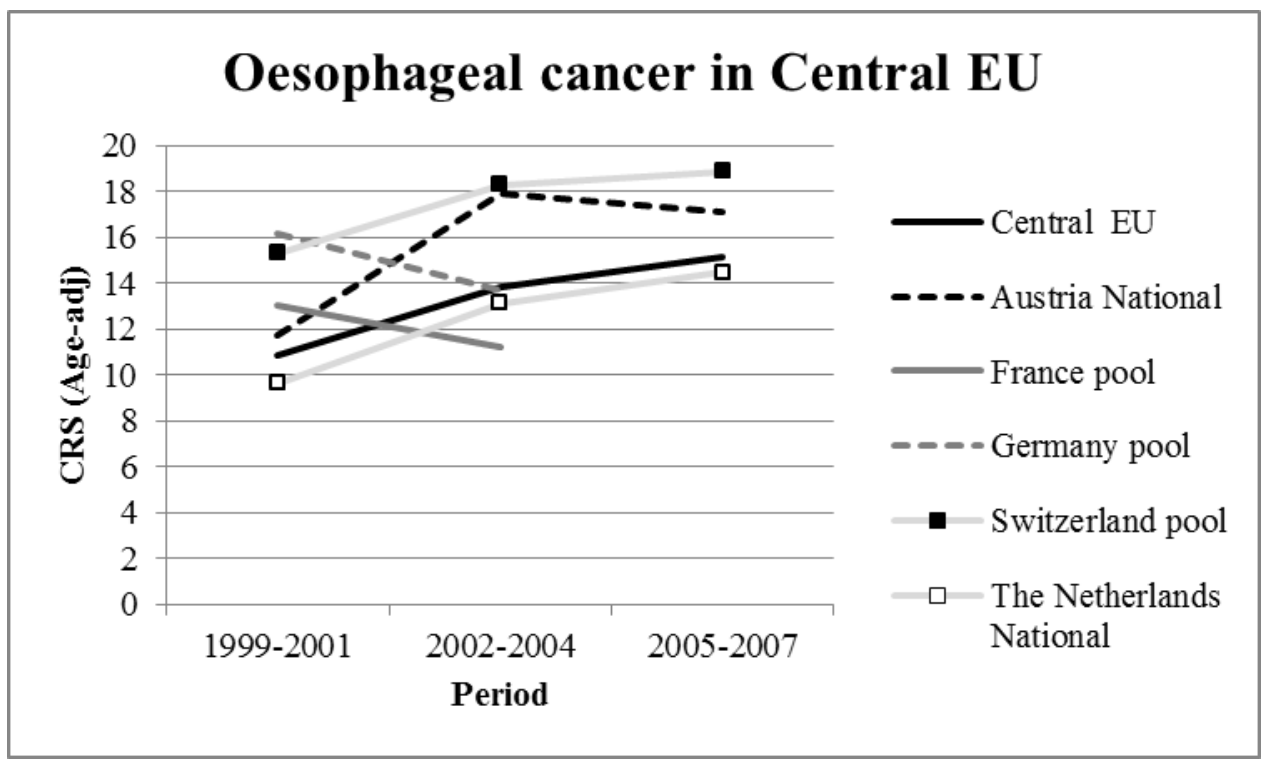

d)

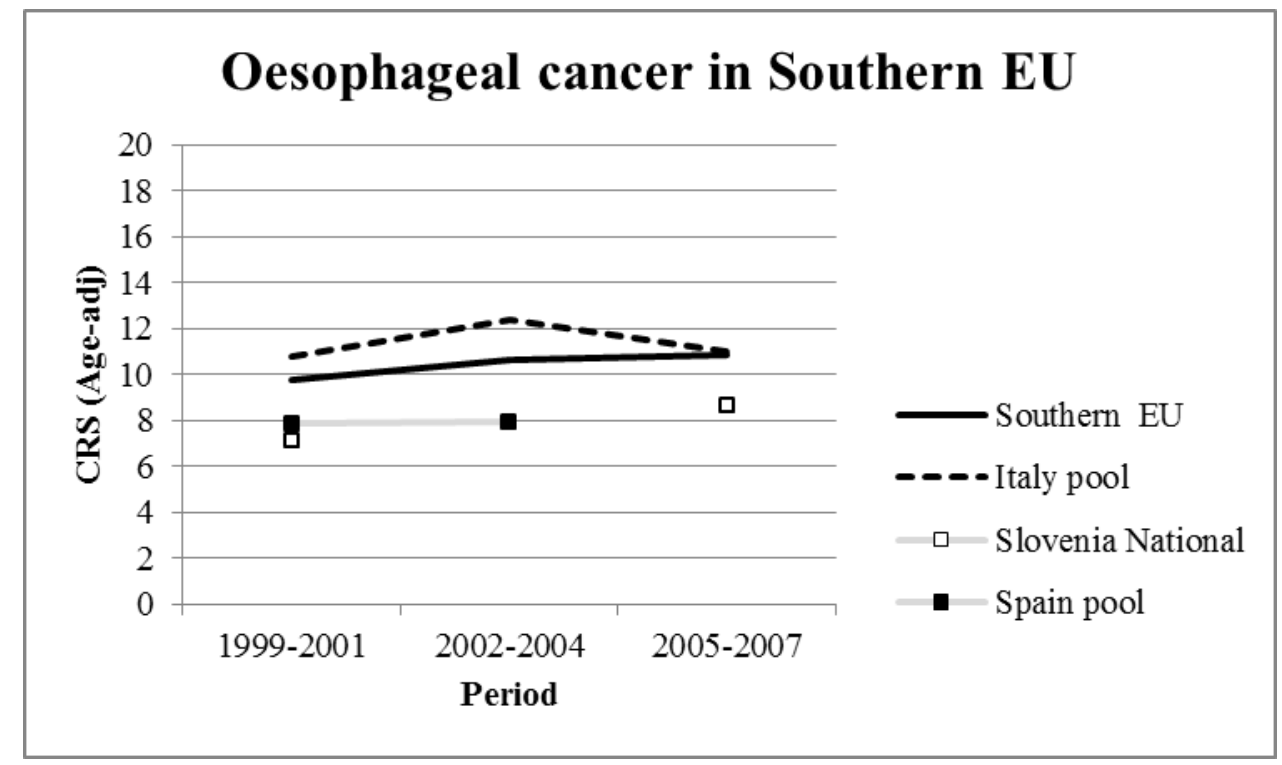

Note: Malta removed as no points are available due to small number of cases 
e)

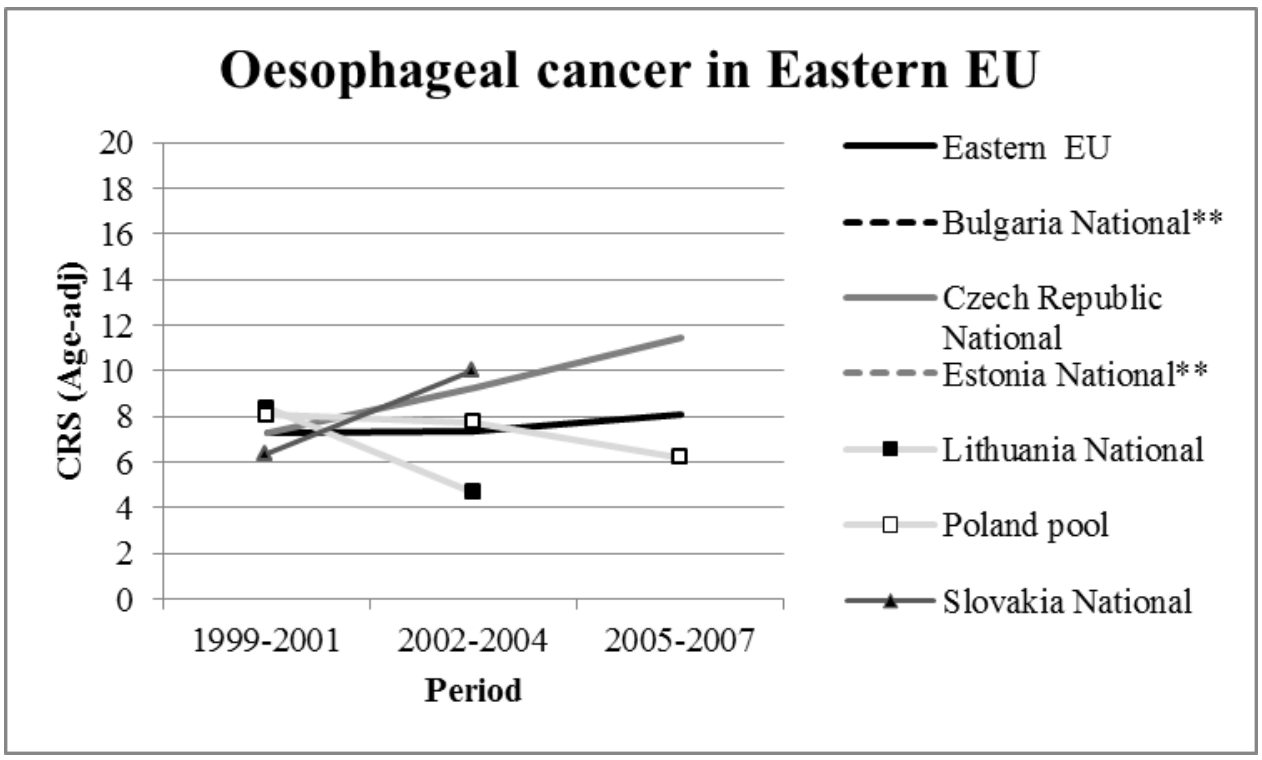

f)

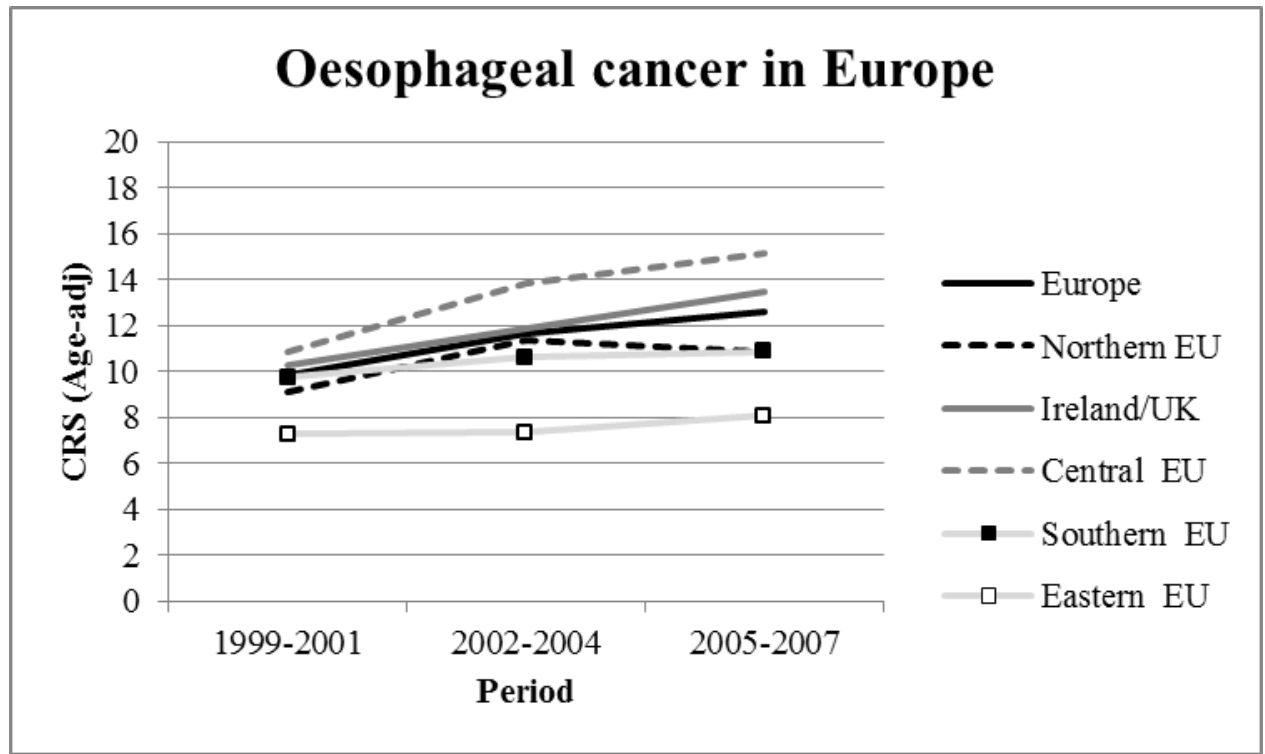


Supplement 2: Age-standardised 5-year RS for stomach cancer in a) Northern Europe, b)

Ireland and UK, c) Central Europe, d) Southern Europe, e) Eastern Europe and f) European average.

a)

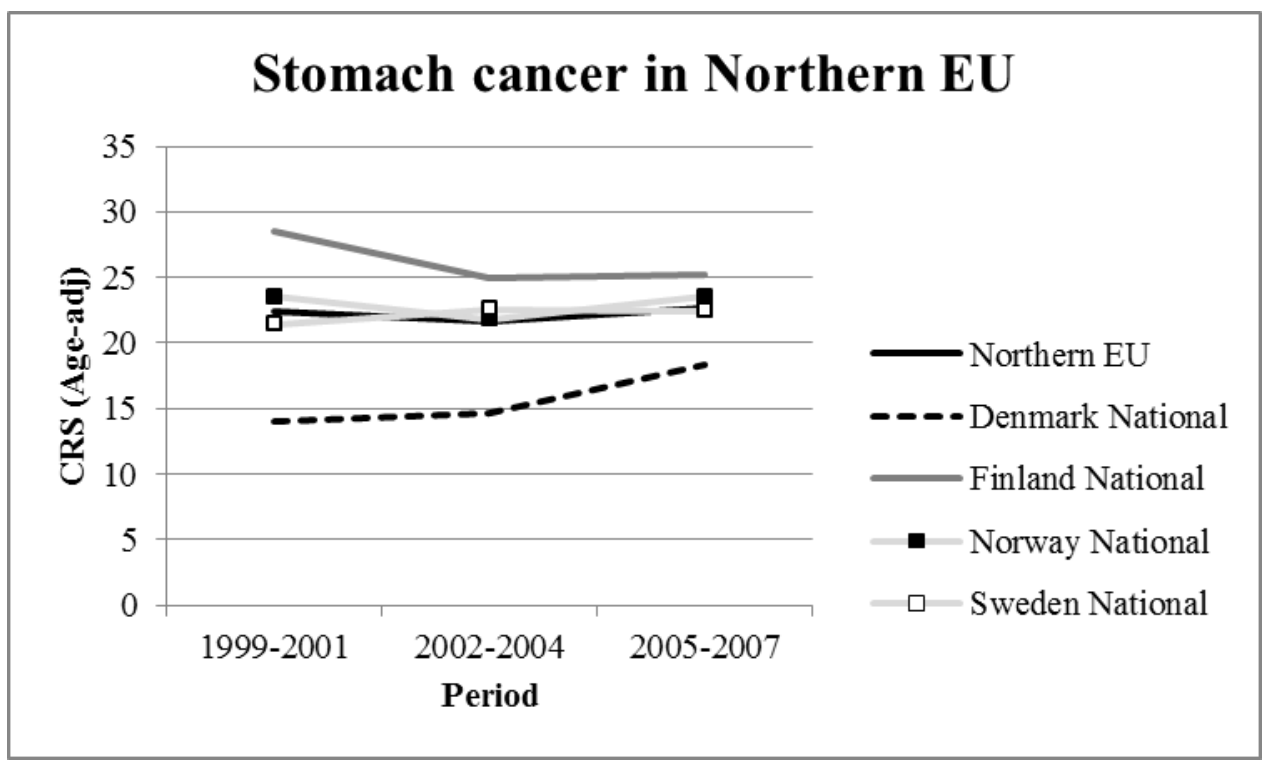

Note: Iceland removed as no points are available due to small number of cases

b)

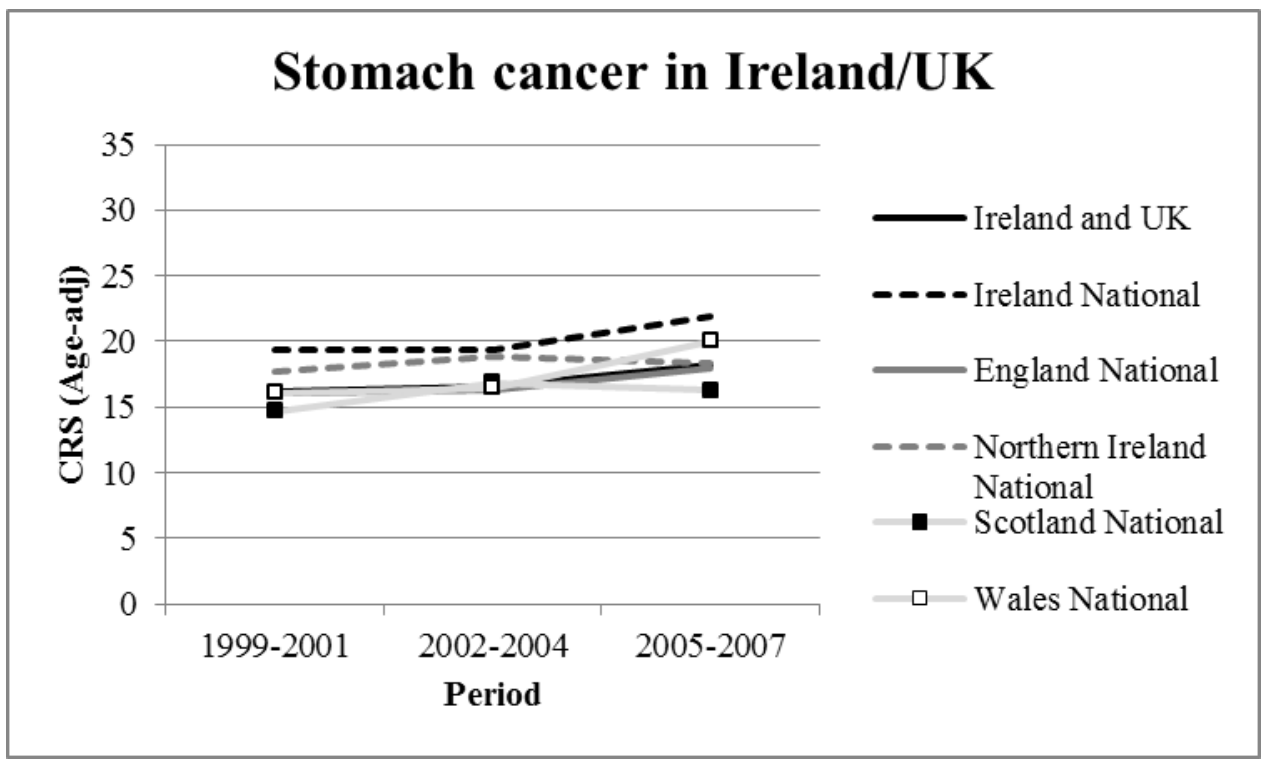


c)

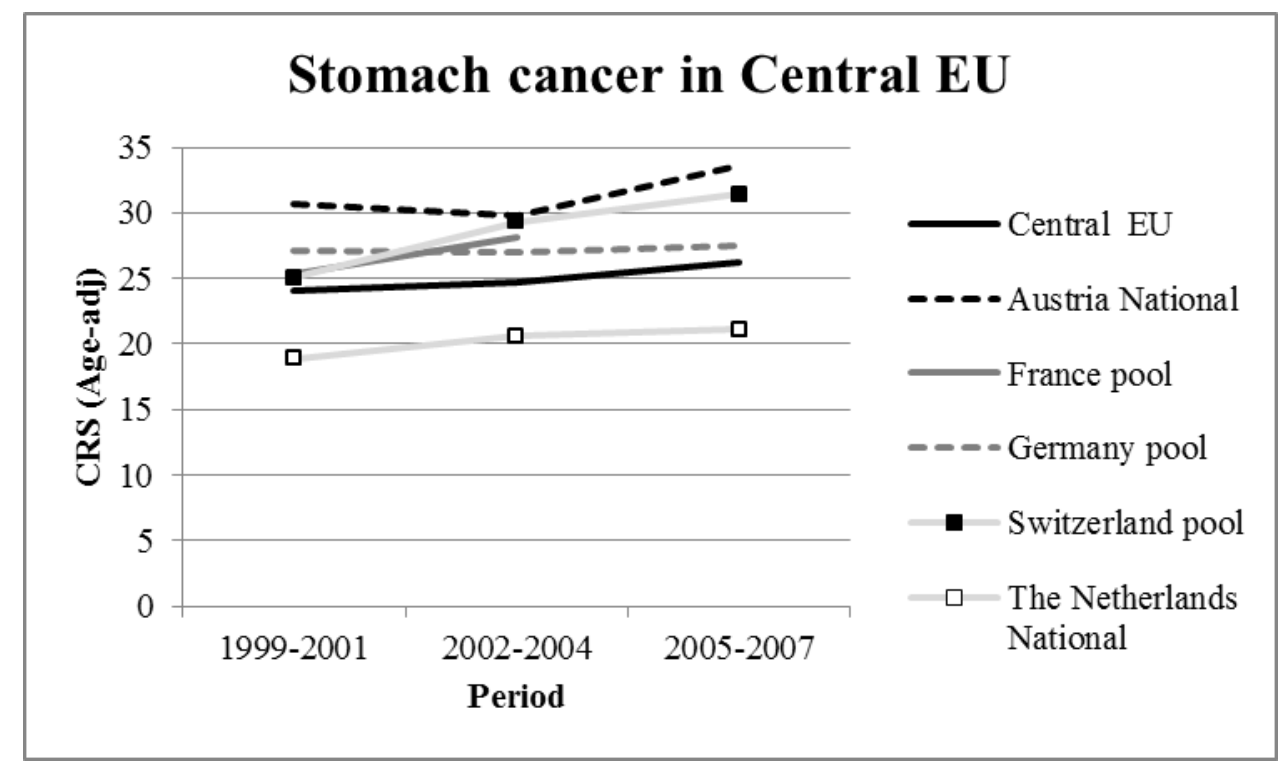

d)

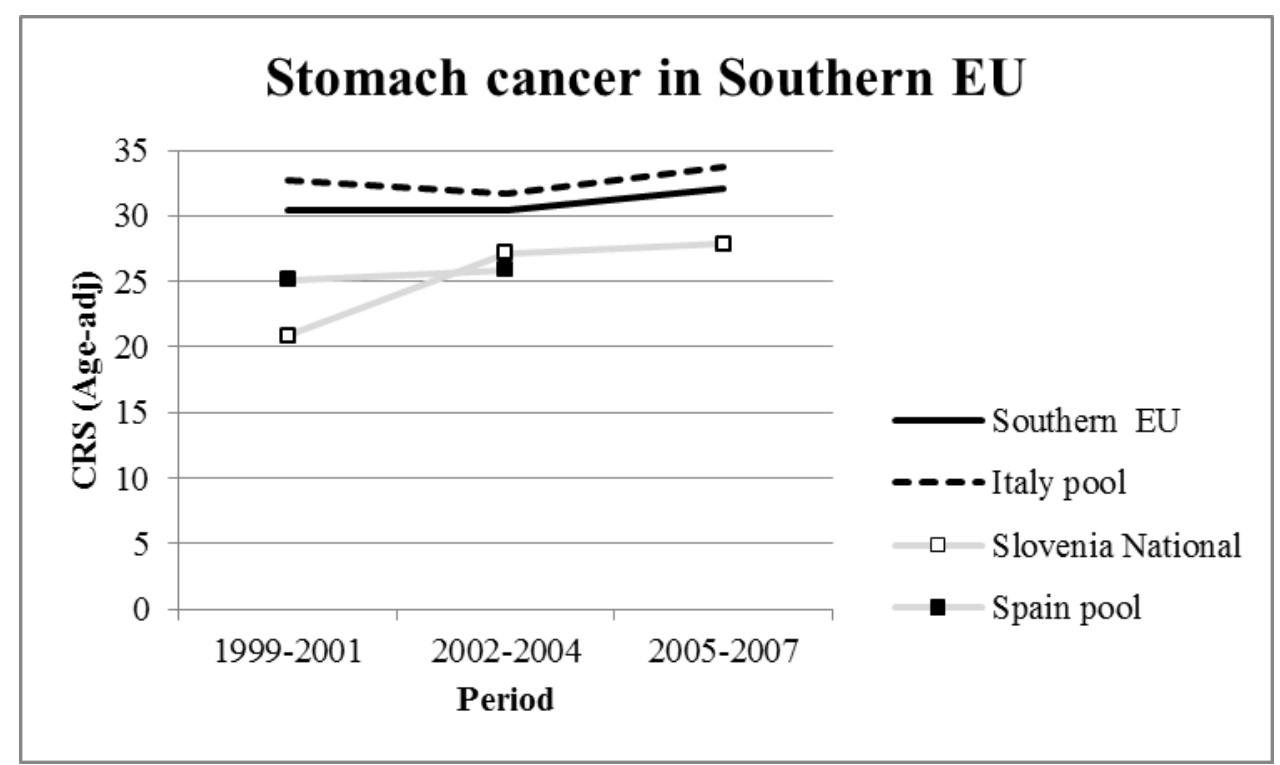

Note: Malta removed as no points are available due to small number of cases. 
e)

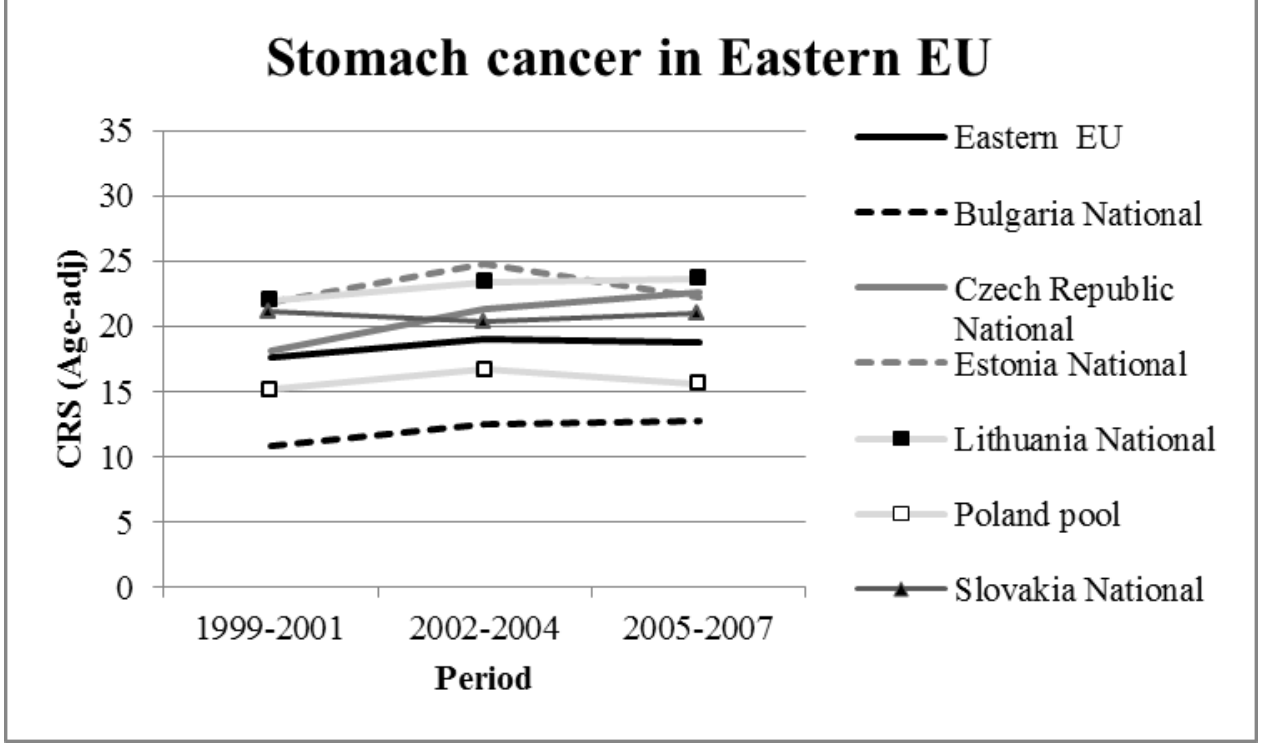

Note: Estonia removed as no points are available due to small number of cases.

f)

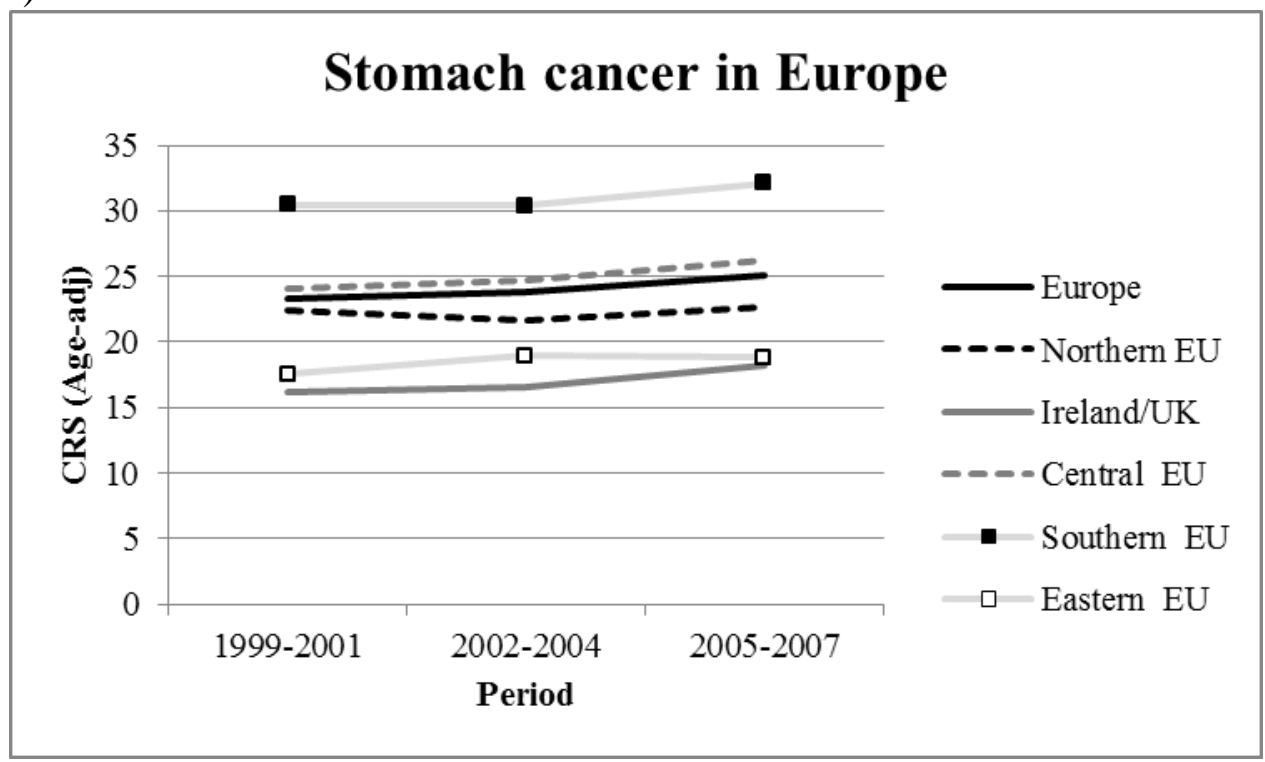

Ref supplement 2 f previously presented de Angelis et al., 2014[3] 
Supplement 3: Age-standardised 5-year RS for small intestine cancer in a)Northern Europe, b) Ireland and UK, c) Central Europe, d) Southern Europe, e) Eastern Europe and f) European average.

a)

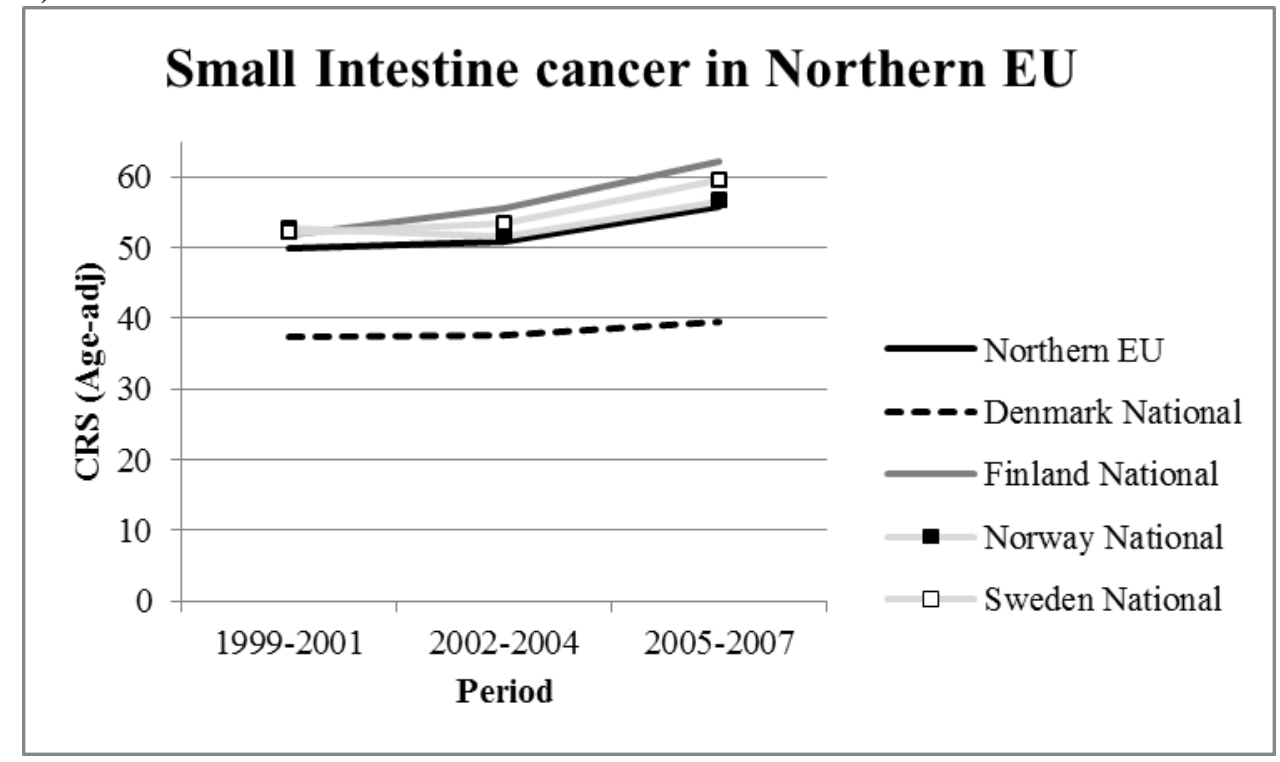

Note: Iceland removed as no points are available due to small number of cases

b)

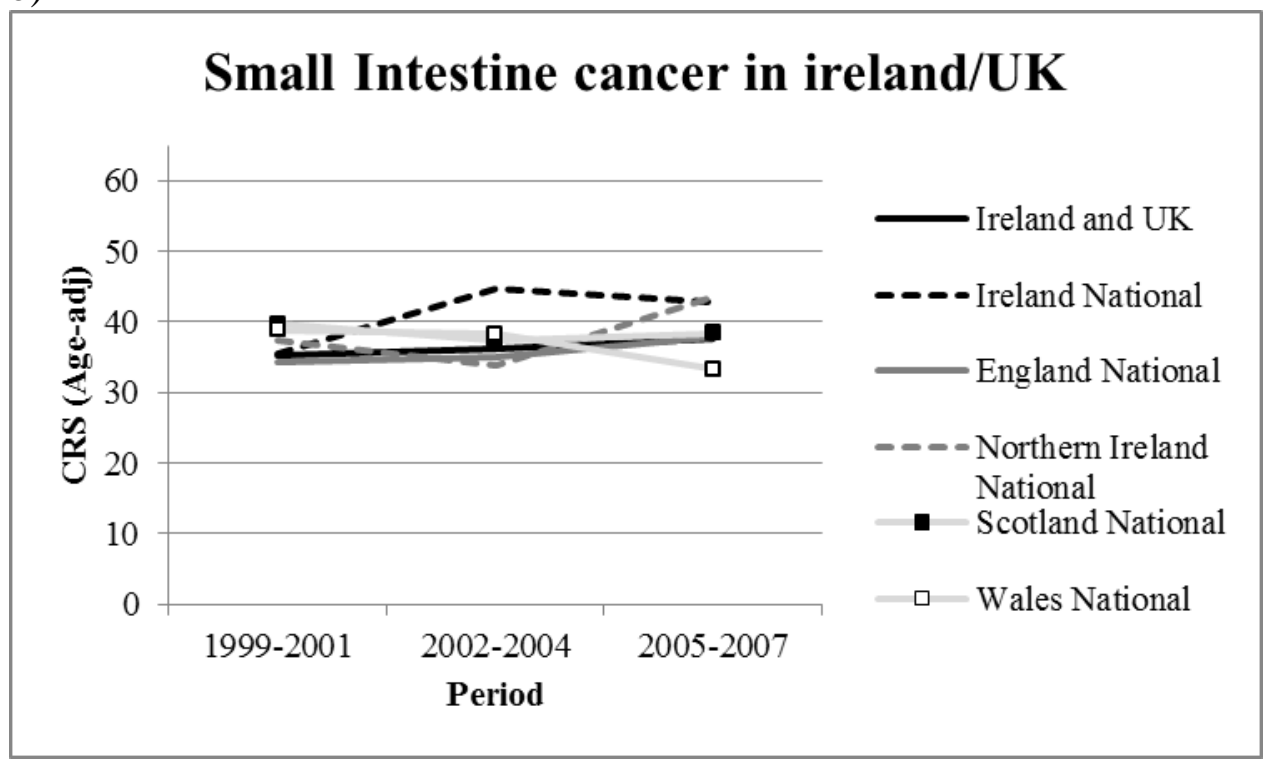


c)

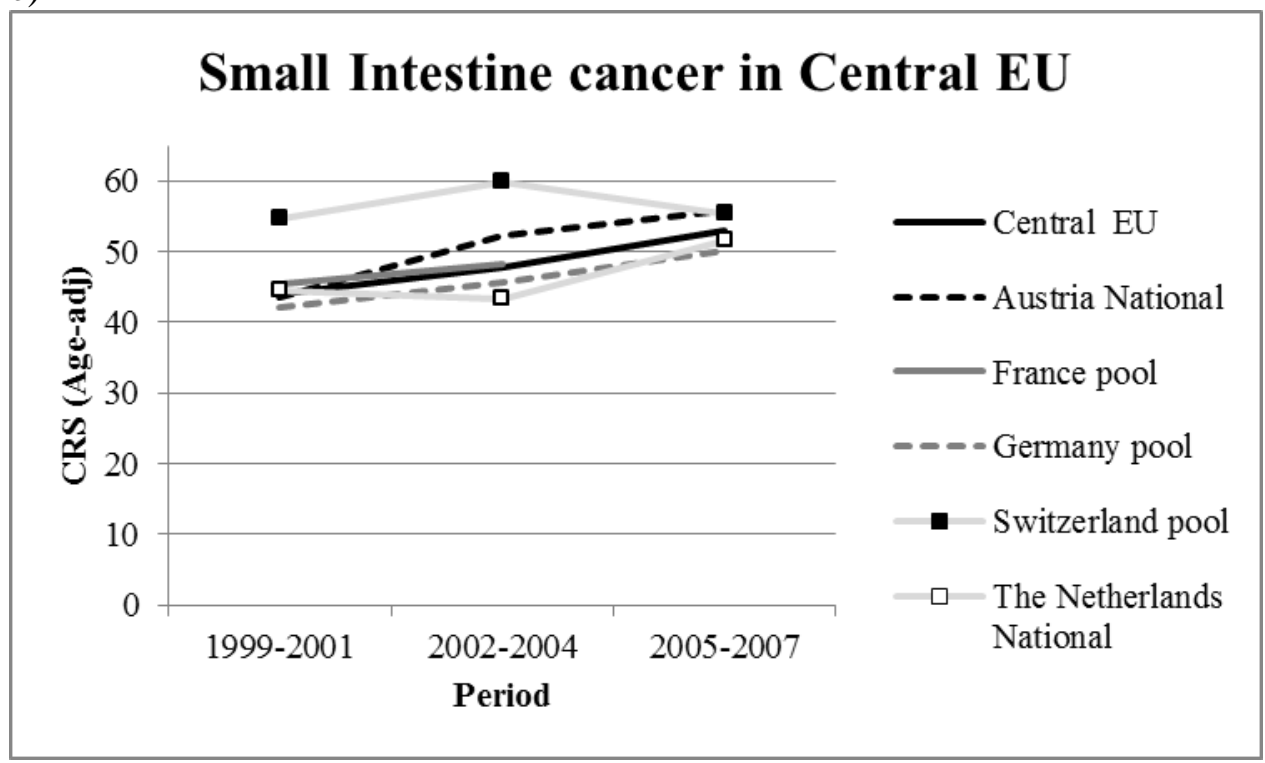

d)

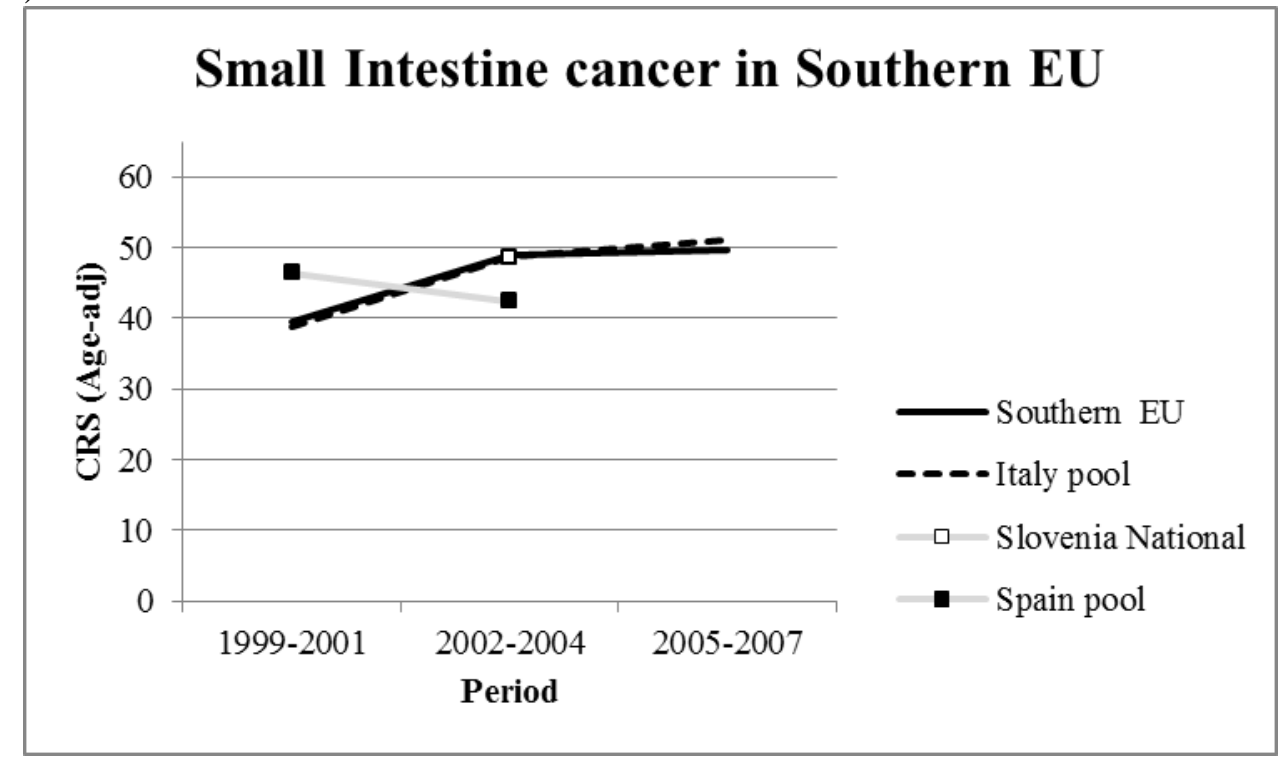

Note: Malta removed as no points are available due to small number of cases. 
e)

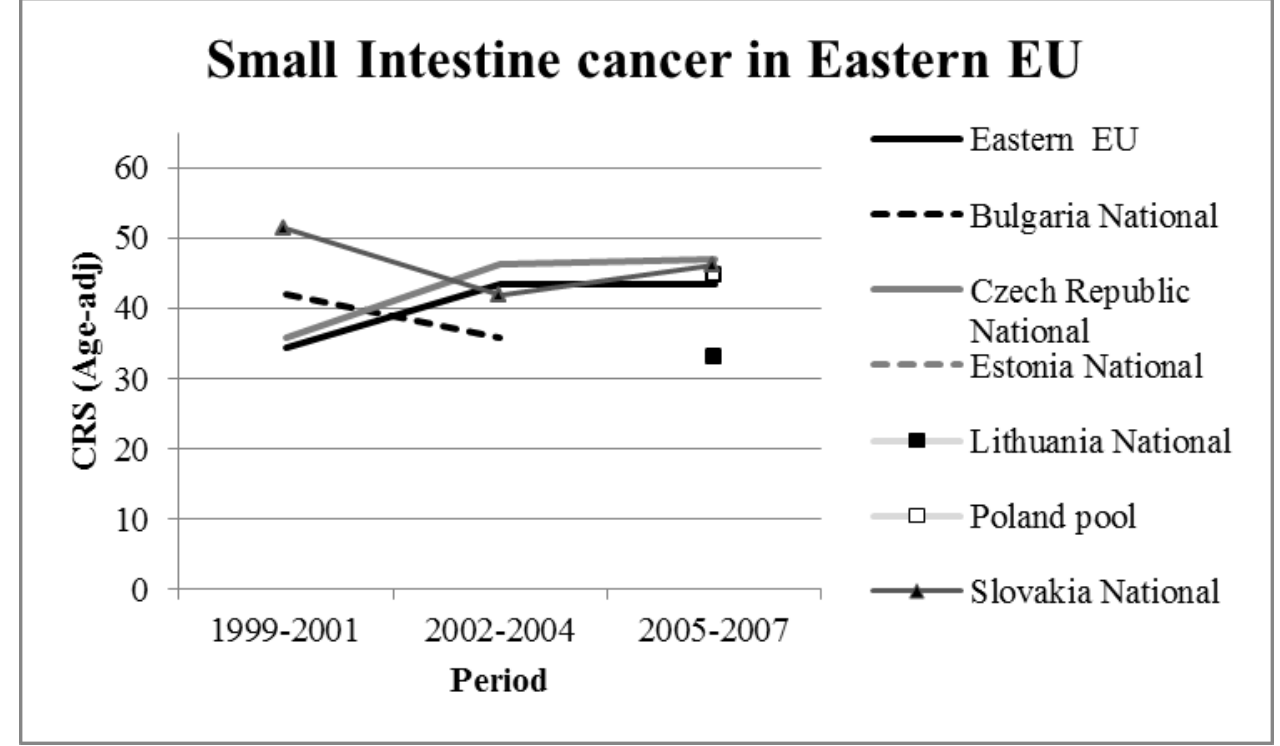

Note: Estonia removed as no points are available due to small number of cases

f)

\section{Small Intestine cancer in Europe}

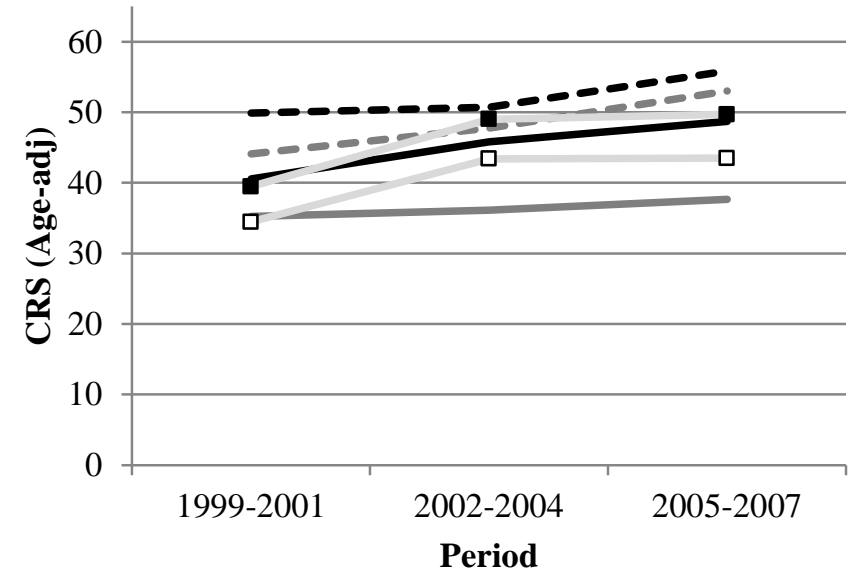

$\longrightarrow$ Europe

- - Northern EU

Ireland/UK

- Central EU

- Southern EU

$\square-$ Eastern EU

Period 


\section{Oesophagus}

Age-standardised 1-year, 5-year relative survival, and 5-year relative survival conditional to surviving 1 year, with $95 \%$ confidence intervals in parentheses

Age-standardised 5-year relative survival (\%)

Number

of cases

1-year

5 -year

Conditional

9 654 35.8(34.8- 36.9) 10.6 ( 9.8- 11.5) 29.6( 27.5- 31.9)

$3,165 \quad 30.0(28.4-31.8) \quad 8.9(\quad 7.7-10.3) \quad 29.6(25.8-33.8)$

$1,798 \quad 38.1(35.6-40.6) \quad 12.0(10.1-14.2) \quad 31.4(26.8-36.8)$

$12043.1(34.2-54.2) \quad-(-)) \quad-(-1)$

$1,442 \quad 38.4(35.7-41.2) \quad 10.0(7.9-12.6) \quad 25.9(20.7-32.5)$

$3,129 \quad 39.2(37.3-41.2) \quad 11.7(10.2-13.3) \quad 29.7(26.3-33.5)$

$63,17939.8(39.4-40.2) \quad 12.5(12.1-12.8) \quad 31.4(30.5-32.2)$

$2,67341.0(39.1-43.0) \quad 15.6(13.9-17.4) \quad 37.9(34.2-42.0)$

$49,287 \quad 39.7(39.2-40.2) \quad 12.4(12.0-12.8) \quad 31.2(30.3-32.2)$

$1,283 \quad 39.0(36.3-42.0) \quad 16.1(13.7-18.9) \quad 41.3(35.8-47.6)$

$6,49240.0(38.6-41.3) \quad 11.0(10.0-12.1) \quad 27.5(25.1-30.2)$

$3,444 \quad 40.4(38.6-42.2) \quad 13.1(11.7-14.8) \quad 32.5(29.1-36.3)$

$32,860 \quad 45.5$ ( $44.9-46.1) \quad 15.3(14.8-15.9) \quad 33.7(32.7-34.7)$

$2,567 \quad 42.8(40.8-44.9) \quad 16.3(14.5-18.3) \quad 38.0(34.3-42.2)$

$3,93651.8(50.2-53.5) \quad 21.8(20.2-23.5) \quad 42.0(39.2-45.0)$

$4,499 \quad 46.7$ ( $45.2-48.3) \quad 13.9(12.7-15.2) \quad 29.7(27.3-32.2)$

$9,038 \quad 46.1(45.0-47.2) \quad 16.2(15.1-17.3) \quad 35.1(33.0-37.3)$

$1,190 \quad 49.6(46.6-52.7) \quad 18.4(15.7-21.7) \quad 37.2(32.1-43.2)$

$11,630 \quad 42.7(41.8-43.7) \quad 13.0(12.2-13.8) \quad 30.4(28.7-32.3)$

$12,22235.5$ ( 34.6-36.4) $\quad 10.1$ ( 3.5 - 10.8) 28.5 ( 27.0- 30.2)

$1,67626.4(24.2-28.8) \quad 10.2(8.3-12.6) \quad 38.7(32.0-46.9)$

$5,488 \quad 40.3(39.0-41.7) \quad 11.7(10.7-12.8) \quad 29.0(26.7-31.5)$

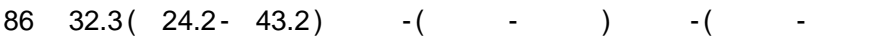

$2,530 \quad 33.5(31.6-35.5) \quad 10.0(8.7-11.6) \quad 29.9(26.1-34.1)$

$71229.6(26.3-33.4) \quad 8.3(6.2-11.2) \quad 28.1(21.4-36.8)$

$\begin{array}{llllll}1,730 & 38.2(35.9-40.7) & 9.3(7.8-11.1) & 24.5(20.8-28.8)\end{array}$

$9,77027.0(26.0-28.0) \quad 7.7(7.0-8.6) \quad 28.7(26.1-31.5)$

$1,145 \quad 17.8\left(\begin{array}{llllll}15.4-20.4) & 6.1(4.3- & 8.6) & 34.4(25.0- & 47.3)\end{array}\right.$

$3,283 \quad 31.2(29.5-33.0) \quad 10.6(9.2-12.2) \quad 34.1(30.0-38.7)$

$426 \quad 28.1(23.7-33.3) \quad 7.0(\quad 4.4-11.2) \quad 24.9\left(\begin{array}{llll}16.0 & -38.7)\end{array}\right.$

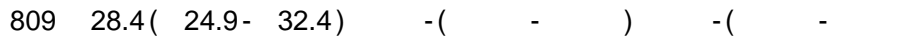

$1,121 \quad 24.0(21.3-27.0) \quad 5.7\left(\begin{array}{lllll}3.9- & 8.3) & 23.7(16.6-33.9)\end{array}\right.$

$1,328 \quad 27.2(24.7-30.1) \quad 6.5\left(\begin{array}{lllll}4 & 4.8-8.7) & 23.8( & 18.0-31.5)\end{array}\right.$

$1,658 \quad 25.7(23.3-28.4) \quad 6.9\left(\begin{array}{lllll}5.2 & -9.2) & 26.8(20.4-35.2)\end{array}\right.$

$127,68539.9$ ( 39.4- 40.4) $12.4(12.0-12.8) \quad 31.0(30.1-31.9)$

\begin{tabular}{|c|c|c|c|c|c|}
\hline ( & 0 & 20 & 40 & 60 & 80 \\
\hline Northern Europe & 7 & & & & \\
\hline Denmark & $\mathrm{H}$ & & & & \\
\hline Finland & H & & & & \\
\hline Iceland & & & & & \\
\hline Norway & $\mapsto$ & & & & \\
\hline Sweden & H & & & & \\
\hline Ireland and UK & 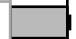 & & & T & \\
\hline Ireland & & $\mathrm{H}$ & & & \\
\hline UK, England & 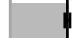 & & & & \\
\hline UK, Northern Ireland & & $\mapsto$ & & & \\
\hline UK, Scotland & H & & & I & \\
\hline UK, Wales & t & t & & & \\
\hline Central Europe & & 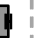 & & 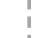 & \\
\hline Austria & & $H^{\prime \prime}$ & & & \\
\hline Belgium & & $\mathrm{H}$ & & & \\
\hline France & 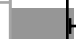 & H & & & \\
\hline Germany & & H & & & \\
\hline Switzerland & & $\mapsto$ & & & \\
\hline The Netherlands & & & & & \\
\hline Southern Europe & 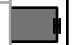 & & & & \\
\hline Croatia & H & & & & \\
\hline Italy & 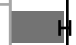 & & & & \\
\hline Malta & & & & & \\
\hline Portugal & $H$ & & & & \\
\hline Slovenia & -1 & & & & \\
\hline Spain & $\mathrm{H}$ & & & & \\
\hline Eastern Europe & & & & & \\
\hline Bulgaria & $H$ & & & & \\
\hline Czech Republic & & & & & \\
\hline Estonia & $t$ & & & & \\
\hline Latvia & & & & & \\
\hline Lithuania & $H$ & & & & \\
\hline Poland & $H$ & & & & \\
\hline Slovakia & $H$ & & & & \\
\hline Europe & & & & & \\
\hline
\end{tabular}

European age-specific and age-standardised observed (obs, \%) and relative (rel, \%) survival

\begin{tabular}{|c|c|c|c|c|c|}
\hline \multirow{2}{*}{$\begin{array}{l}\text { Age } \\
\text { group } \\
15-44\end{array}$} & \multirow{2}{*}{$\begin{array}{r}\begin{array}{r}\text { Number } \\
\text { of cases }\end{array} \\
2,995\end{array}$} & \multicolumn{4}{|c|}{ 1-year 3-year 5-year } \\
\hline & & obs & 51.1 & 26.8 & 20.9 \\
\hline & & rel & 51.2 & 27.0 & 21.1 \\
\hline \multirow[t]{2}{*}{$45-54$} & 14,298 & obs & 46.6 & 19.4 & 14.4 \\
\hline & & rel & 46.9 & 19.7 & 14.8 \\
\hline \multirow[t]{2}{*}{$55-64$} & 30,054 & obs & 45.2 & 18.6 & 13.5 \\
\hline & & rel & 45.6 & 19.2 & 14.3 \\
\hline \multirow[t]{2}{*}{$65-74$} & 36,782 & obs & 39.3 & 16.1 & 11.2 \\
\hline & & rel & 40.3 & 17.5 & 12.9 \\
\hline \multirow[t]{2}{*}{$75+$} & 43,556 & obs & 27.0 & 8.3 & 4.7 \\
\hline & & rel & 29.2 & 10.5 & 7.2 \\
\hline \multirow[t]{2}{*}{ All cases } & 127,685 & obs & 38.8 & 15.6 & 10.9 \\
\hline & & rel & 39.9 & 16.8 & 12.4 \\
\hline \multicolumn{6}{|c|}{ Men (71\%) } \\
\hline \multirow[t]{2}{*}{$15-44$} & 2,401 & obs & 49.9 & 25.7 & 19.7 \\
\hline & & rel & 50.0 & 25.9 & 19.9 \\
\hline \multirow[t]{2}{*}{$45-54$} & 11,784 & obs & 46.0 & 18.6 & 13.6 \\
\hline & & rel & 46.2 & 18.9 & 14.0 \\
\hline \multirow[t]{2}{*}{$55-64$} & 24,050 & obs & 44.3 & 17.9 & 12.7 \\
\hline & & rel & 44.8 & 18.6 & 13.6 \\
\hline \multirow[t]{2}{*}{$65-74$} & 27,393 & obs & 39.1 & 15.5 & 10.5 \\
\hline & & rel & 40.2 & 16.9 & 12.3 \\
\hline \multirow[t]{2}{*}{$75+$} & 24,766 & obs & 27.4 & 8.1 & 4.6 \\
\hline & & rel & 29.9 & 10.5 & 7.2 \\
\hline \multirow[t]{2}{*}{ All cases } & 90,394 & obs & 38.5 & 15.0 & 10.3 \\
\hline & & rel & 39.7 & 16.3 & 11.9 \\
\hline \multicolumn{6}{|c|}{ Women (29\%) } \\
\hline \multirow[t]{2}{*}{$15-44$} & 594 & obs & 56.6 & 32.2 & 27.6 \\
\hline & & rel & 56.7 & 32.3 & 27.8 \\
\hline \multirow[t]{2}{*}{$45-54$} & 2,514 & obs & 50.6 & 24.6 & 20.8 \\
\hline & & rel & 50.7 & 24.8 & 21.1 \\
\hline \multirow[t]{2}{*}{$55-64$} & 6,004 & obs & 50.6 & 23.1 & 18.8 \\
\hline & & rel & 50.9 & 23.5 & 19.4 \\
\hline \multirow[t]{2}{*}{$65-74$} & 9,389 & obs & 40.0 & 19.0 & 14.1 \\
\hline & & rel & 40.6 & 19.8 & 15.4 \\
\hline \multirow[t]{2}{*}{$75+$} & 18,789 & obs & 26.4 & 8.6 & 5.0 \\
\hline & & rel & 28.4 & 10.6 & 7.1 \\
\hline All cases & 37,290 & obs & 40.9 & 18.5 & 14.3 \\
\hline
\end{tabular}


Stomach

Age-standardised 1-year, 5-year relative survival, and 5-year relative survival conditional to surviving 1 year, with $95 \%$ confidence intervals in parentheses

Number

of cases

1-year

5 -year

Conditional

$22,18646.9$ ( $46.2-47.6) \quad 21.9$ ( 21.2 - 22.6) $46.6(45.3-47.9)$

$\begin{array}{llllll}4,188 & 39.4(37.9-41.0) & 16.0(14.7-17.5) & 40.6(37.6-43.9)\end{array}$

$5,61649.1(47.8-50.5) \quad 25.3(23.9-26.7) \quad 51.4(49.0-54.0)$

$275 \quad 54.5(48.5-61.3) \quad 34.5(28.3-42.1) \quad 63.3(53.9-74.2)$

$4,45249.0$ ( $47.4-50.7) \quad 22.7(21.1-24.4) \quad 46.3(43.4-49.3)$

$7,655 \quad 48.3(47.1-49.6) \quad 21.7(20.5-22.9) \quad 44.9(42.7-47.2)$

$70,341 \quad 42.1(41.7-42.5) \quad 17.2(16.8-17.5) \quad 40.8(40.0-41.6)$

$3,616 \quad 42.3(40.6-44.0) \quad 20.3(18.7-22.1) \quad 48.1(44.7-51.6)$

$53,998 \quad 42.3(41.8-42.8) \quad 17.0(16.6-17.4) \quad 40.2(39.3-41.2)$

$1,854 \quad 41.5(39.0-44.0) \quad 18.1(15.9-20.5) \quad 43.6(38.9-48.8)$ $6,713 \quad 40.4(39.1-41.7) \quad 16.1(15.0-17.3) \quad 39.9(37.3-42.6)$

$4,160 \quad 42.3(40.6-44.1) \quad 17.8(16.2-19.5) \quad 42.0(38.7-45.7)$

$68,234 \quad 53.3(52.9-53.7) \quad 28.1(27.6-28.5) \quad 52.7(52.0-53.4)$

$10,56954.8(53.8-55.8) \quad 31.0(29.9-32.2) \quad 56.6(54.9-58.5)$

$6,650 \quad 56.2(54.9-57.5) \quad 30.5(29.1-32.0) \quad 54.4(52.2-56.7)$

$6,08454.8(53.5-56.2) \quad 26.3(25.0-27.7) \quad 47.9(45.8-50.1)$

$26,66256.3(55.7-56.9) \quad 31.3(30.6-32.0) \quad 55.6(54.5-56.7)$

$2,146 \quad 57.7(55.5-59.9) \quad 31.6(29.3-34.2) \quad 54.9(51.3-58.7)$

$16,123 \quad 45.2(44.4-46.0) \quad 20.4(19.7-21.3) \quad 45.3(43.7-46.8)$

$68,21352.2(51.9-52.6) \quad 29.6(29.2-30.0) \quad 56.7(56.0-57.4)$

$8,397 \quad 38.4(37.3-39.5) \quad 21.3(20.2-22.5) \quad 55.6(53.2-58.1)$

$35,42856.6(56.0-57.2) \quad 32.4(31.7-33.0) \quad 57.2(56.2-58.1)$

$34041.0(35.7-47.1) \quad 18.7(14.5-24.0) \quad 45.5(36.9-56.2)$

$14,12753.9(53.0-54.7) \quad 31.8(30.9-32.7) \quad 59.0(57.6-60.5)$

$3,617 \quad 46.0$ ( $44.3-47.7) \quad 26.6(24.9-28.5) \quad 57.9(54.7-61.2)$

$6,304 \quad 49.4(48.1-50.7) \quad 25.6(24.3-26.9) \quad 51.8(49.7-54.0)$

$50,775 \quad 38.4$ ( $38.0-38.9) \quad 18.8(18.4-19.2) \quad 48.9(48.0-49.9)$

$11,61428.8$ ( $27.9-29.6) \quad 11.9(11.2-12.7) \quad 41.4(39.1-43.9)$

$12,354 \quad 41.8(40.9-42.8) \quad 22.0(21.1-23.0) \quad 52.7(50.8-54.6)$

$3,242 \quad 44.4$ ( $42.7-46.2) \quad 22.8(21.0-24.8) \quad 51.4(47.9-55.2)$

$4,842 \quad 38.3(36.9-39.7) \quad 20.2(18.8-21.7) \quad 52.7(49.5-56.1)$

$6,741 \quad 42.5(41.3-43.7) \quad 23.1(21.9-24.4) \quad 54.3(51.9-56.9)$

$6,112 \quad 38.1(36.8-39.4) \quad 15.6(14.4-16.8) \quad 40.8(38.2-43.7)$

$5,870 \quad 43.5(42.2-44.8) \quad 20.9\left(\begin{array}{lllll}19.6 & -22.2) & 48.0(45.5-50.6)\end{array}\right.$

$279,749 \quad 49.7(49.4-50.0) \quad 25.1(24.8-25.4) \quad 50.6(50.1-51.1)$
European age-specific and age-standardised observed (obs, \%) and relative (rel, \%) survival

Age Number 1-year 3-year 5-year

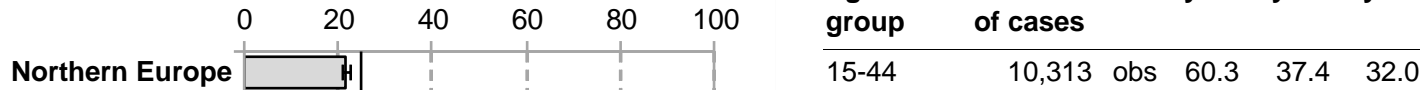

$\begin{array}{llll}\text { rel } \quad 60.4 & 37.5 & 32.3\end{array}$

$\begin{array}{llllll}45-54 & 22,471 & \text { obs } & 59.0 & 35.6 & 29.8\end{array}$

rel $\quad 59.3 \quad 36.1 \quad 30.5$

$\begin{array}{llllll}55-64 & 47,246 & \text { obs } & 55.8 & 33.6 & 27.5\end{array}$

rel $\quad \begin{array}{lll}56.4 & 34.7 & 29.1\end{array}$

65-74 $\quad 84,324$ obs $48.9 \quad 27.6 \quad 21.9$ rel $\quad 50.1 \quad 29.8 \quad 25.1$

$\begin{array}{llllll}75+ & 115,395 & \text { obs } & 34.2 & 16.6 & 11.7\end{array}$ $\begin{array}{llll}\text { rel } & 37.3 & 21.3 & 18.1\end{array}$

UK, Scotland

UK, Wales

Central Europe

Austria

Belgium

France

Germany

Switzerland

The Netherlands

Southern Europe

Croatia

Italy

Malta

Portugal

Slovenia

Spain

\section{Eastern Europe}

Bulgaria

Czech Republic

Estonia

Latvia

Lithuania

Poland

Slovakia

Europe obs $\quad 48.3 \quad 27.4 \quad 21.9$

$\begin{array}{rrrrrr}\text { All cases } \quad 279,749 \text { obs } & 48.3 & 27.4 & 21.9 \\ & \text { rel } & 49.7 & 29.8 & 25.1\end{array}$

Men (61\%)

15-44

$\begin{array}{llll}5,712 \text { obs } & 59.1 & 35.9 & 30.4\end{array}$

$\begin{array}{llll}\text { rel } & 59.2 & 36.1 & 30.8\end{array}$

45-54 $\quad 14,758$ obs $58.0 \quad 34.4 \quad 28.3$ $\begin{array}{llll}\text { rel } \quad 58.3 & 35.0 & 29.2\end{array}$

55-64 $\quad 32,479$ obs $\quad 54.6 \quad 31.8 \quad 25.8$ $\begin{array}{llll}\text { rel } \quad 55.3 & 33.0 & 27.6\end{array}$

$\begin{array}{llllll}65-74 & 55,667 & \text { obs } & 47.9 & 25.7 & 19.9\end{array}$

$\begin{array}{llll}\text { rel } & 49.4 & 28.2 & 23.4\end{array}$

$\begin{array}{llllll}75+ & 61,560 & \text { obs } & 33.7 & 15.4 & 10.5\end{array}$

$\begin{array}{llll}\text { rel } & 36.9 & 20.4 & 17.0\end{array}$

$\begin{array}{llllll}\text { All cases } \quad 170,176 \text { obs } & 47.3 & 25.9 & 20.3\end{array}$

$\begin{array}{llll}\text { rel } & 48.9 & 28.4 & 23.7\end{array}$

Women (39\%)

\begin{tabular}{llllll}
\hline $15-44$ & 4,601 & obs & 61.9 & 39.3 & 34.1
\end{tabular}

$\begin{array}{llll}\text { rel } \quad 62.0 & 39.4 & 34.2\end{array}$

$\begin{array}{llllll}45-54 & 7,713 & \text { obs } & 60.9 & 37.9 & 32.6\end{array}$

rel $\quad \begin{array}{lll}61.1 & 38.2 & 33.1\end{array}$

55-64 $\quad 14,767$ obs $\quad 58.6 \quad 37.8 \quad 31.5$

$\begin{array}{llll}\text { rel } \quad 58.9 & 38.5 & 32.5\end{array}$

65-74 28.657 obs $\quad 50.8 \quad 31.5 \quad 26.2$

rel $\quad \begin{array}{lll}51.5 & 33.0 & 28.5\end{array}$

$\begin{array}{llllll}75+ & 53,835 & \text { obs } & 34.9 & 18.0 & 13.1\end{array}$

$\begin{array}{llll}\text { rel } \quad 37.7 & 22.4 & 19.2\end{array}$

$\begin{array}{llllll}\text { All cases } \quad 109,573 \text { obs } & 50.0 & 30.3 & 24.9\end{array}$ 


\section{Small intestine}

Age-standardised 1-year, 5-year relative survival, and 5-year relative survival conditional to surviving 1 year, with $95 \%$ confidence intervals in parentheses

Number

cases 1-year 5-year Conditional

Northern Europe

73.5( 72.1- 75.0) 52.5 ( 50.5- 54.6) 71.5( 69.1- 73.9)

$600 \quad 59.8(56.0-63.7) \quad 36.8$ ( $32.4-41.9) \quad 61.6(55.1-69.0)$

$64476.0(72.7-79.5) \quad 56.0(51.2-61.2) \quad 73.7(68.2-79.6)$

$44 \quad 77.5(64.7-92.9) \quad 45.3(31.2-65.7) \quad 58.4(42.2-80.8)$

$82175.1(72.1-78.1) \quad 55.0(50.8-59.4) \quad 73.2(68.4-78.3)$

$1,71976.2(74.2-78.3) \quad 55.7(52.7-58.9) \quad 73.0(69.5-76.7)$

$6,948 \quad 58.8(57.6-59.9) \quad 36.9(35.5-38.3) \quad 62.8(60.7-64.9)$

$38366.1(61.5-71.0) \quad 43.0(37.2-49.8) \quad 65.1(57.3-73.9)$

$5,361 \quad 57.5(56.2-58.9) \quad 36.4(34.9-38.1) \quad 63.3(61.0-65.7)$

$18757.1(50.3-64.7) \quad 34.6(26.9-44.5) \quad 60.6(48.8-75.3)$

$61263.8(60.1-67.8) \quad 38.4(33.6-43.8) \quad 60.1(53.4-67.6)$

$40561.7(57.1-66.6) \quad 37.3(31.7-43.8) \quad 60.4(52.4-69.6)$

$6,754 \quad 74.1(73.1-75.2) \quad 53.9\left(\begin{array}{lllll}52.4 & -55.4) & 72.7(70.9-74.5\end{array}\right.$

$88974.7(71.8-77.7) \quad 54.6(50.6-59.0) \quad 73.1(68.4-78.1)$

$84175.1(72.2-78.1) \quad 55.8(51.7-60.3) \quad 74.3(69.6-79.4)$

$80274.4(71.3-77.5) \quad 50.8(47.0-55.0) \quad 68.4(63.9-73.1)$

$2,151 \quad 77.2(75.4-79.1) \quad 57.7(54.9-60.7) \quad 74.7(71.5-78.1)$

$348 \quad 78.9(74.7-83.4) \quad 58.6(52.4-65.4) \quad 74.2(67.4-81.6)$

$1,72368.5(66.3-70.8) \quad 48.9(46.0-52.1) \quad 71.4(67.7-75.4)$

$3,677 \quad 66.2$ ( $64.7-67.7) \quad 46.8$ ( $44.9-48.7) \quad 70.6$ ( 68.3- 73.1)

28653.3 ( $47.9-59.4) \quad 42.3(35.4-50.6) \quad 79.4(68.8-91.5)$

$2,206 \quad 69.7(67.8-71.6) \quad 49.0(46.7-51.6) \quad 70.4(67.5-73.4)$

$3068.7(51.2-92.2) \quad 23.5(13.4-40.9) \quad 34.1(21.3-54.7)$

$626 \quad 62.3(58.6-66.2) \quad 42.4(38.0-47.3) \quad 68.1(62.1-74.6)$

$15864.5(57.6-72.2) \quad 44.4(36.1-54.8) \quad 68.9(57.8-82.2)$

$37161.5(56.8-66.6) \quad 45.4(40.1-51.3) \quad 73.7(67.2-81.0)$

$2,07161.4(59.2-63.6) \quad 43.0(40.1$ - 46.0) $\quad 70.0(66.1$ - 74.2)

$26255.5(49.1-62.8) \quad 36.6(28.5-46.8) \quad 65.9(53.1-81.7)$

$89064.6(61.5-67.9) \quad 47.4(43.1-52.2) \quad 73.4(67.6-79.7)$

$8764.4(54.6-76.0) \quad 42.2(29.7-60.1) \quad 65.5(48.0-89.6)$

$10153.7(44.3-65.1) \quad 39.6(28.7-54.6) \quad 73.7(56.9-95.3)$

16156.8 ( $49.4-65.2) \quad 32.5(24.8-42.7) \quad 57.3(45.3-72.3)$

$22958.3(52.0-65.3) \quad 40.0(32.7-49.0) \quad 68.7(58.0-81.3)$

$34163.2(58.1-68.9) \quad 46.3(39.8-53.9) \quad 73.2(64.5-83.0)$

$23,27867.9(67.0-68.9) \quad 47.9(46.7-49.1) \quad 70.5(69.0-72.0)$
European age-specific and age-standardised observed (obs, \%) and relative (rel, \%) survival

\begin{tabular}{|c|c|c|c|c|c|}
\hline \multirow{2}{*}{$\begin{array}{l}\begin{array}{l}\text { Age } \\
\text { group }\end{array} \\
15-44\end{array}$} & \multirow{2}{*}{$\begin{array}{r}\begin{array}{r}\text { Number } \\
\text { of cases }\end{array} \\
1,490\end{array}$} & \multicolumn{3}{|c|}{ 1-year 3-year } & 5-year \\
\hline & & obs & 86.2 & 72.5 & 67.3 \\
\hline & & rel & 86.3 & 72.8 & 67.9 \\
\hline \multirow[t]{2}{*}{$45-54$} & 2,756 & obs & 82.5 & 67.9 & 59.7 \\
\hline & & rel & 82.9 & 68.9 & 61.2 \\
\hline \multirow[t]{2}{*}{$55-64$} & 5,141 & obs & 74.6 & 58.8 & 51.0 \\
\hline & & rel & 75.3 & 60.6 & 53.8 \\
\hline \multirow[t]{2}{*}{$65-74$} & 6,577 & obs & 66.5 & 49.2 & 41.0 \\
\hline & & rel & 68.0 & 52.8 & 46.6 \\
\hline \multirow[t]{2}{*}{$75+$} & 7,314 & obs & 47.7 & 28.9 & 23.0 \\
\hline & & rel & 51.4 & 36.2 & 34.2 \\
\hline \multirow[t]{2}{*}{ All cases } & 23,278 & obs & 66.2 & 49.4 & 42.2 \\
\hline & & rel & 67.9 & 53.1 & 47.9 \\
\hline \multicolumn{6}{|c|}{ Men (54\%) } \\
\hline \multirow[t]{2}{*}{$15-44$} & 816 & obs & 84.4 & 68.1 & 63.9 \\
\hline & & rel & 84.5 & 68.5 & 64.6 \\
\hline \multirow[t]{2}{*}{$45-54$} & 1,663 & obs & 81.3 & 65.8 & 58.3 \\
\hline & & rel & 81.7 & 66.9 & 60.1 \\
\hline \multirow[t]{2}{*}{$55-64$} & 2,977 & obs & 72.5 & 55.9 & 46.8 \\
\hline & & rel & 73.3 & 58.1 & 50.0 \\
\hline \multirow[t]{2}{*}{$65-74$} & 3,729 & obs & 65.4 & 47.3 & 39.1 \\
\hline & & rel & 67.3 & 51.7 & 46.0 \\
\hline \multirow[t]{2}{*}{$75+$} & 3,416 & obs & 47.7 & 27.3 & 22.6 \\
\hline & & rel & 52.0 & 35.5 & 35.9 \\
\hline \multirow[t]{2}{*}{ All cases } & 12,601 & obs & 65.1 & 47.1 & 40.1 \\
\hline & & rel & 67.2 & 51.5 & 47.0 \\
\hline \multicolumn{6}{|c|}{ Women (46\%) } \\
\hline \multirow[t]{2}{*}{$15-44$} & 674 & obs & 89.1 & 78.4 & 71.7 \\
\hline & & rel & 89.2 & 78.6 & 72.1 \\
\hline \multirow[t]{2}{*}{$45-54$} & 1,093 & obs & 84.5 & 71.3 & 62.4 \\
\hline & & rel & 84.7 & 71.9 & 63.3 \\
\hline \multirow[t]{2}{*}{$55-64$} & 2,164 & obs & 77.7 & 63.6 & 57.4 \\
\hline & & rel & 78.1 & 64.7 & 59.3 \\
\hline \multirow[t]{2}{*}{$65-74$} & 2,848 & obs & 67.8 & 51.7 & 43.7 \\
\hline & & rel & 68.8 & 54.1 & 47.6 \\
\hline \multirow[t]{2}{*}{$75+$} & 3,897 & obs & 47.8 & 30.1 & 24.3 \\
\hline & & rel & 51.0 & 36.5 & 33.9 \\
\hline \multirow[t]{2}{*}{ All cases } & 10,676 & obs & 67.8 & 52.4 & 45.4 \\
\hline & & rel & 69.1 & 55.3 & 49.9 \\
\hline
\end{tabular}

